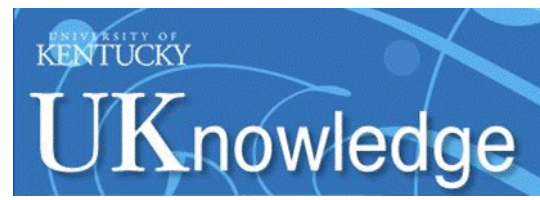

University of Kentucky

UKnowledge

\title{
Focused Electron Beam Induced Deposition of Copper with High Resolution and Purity from Aqueous Solutions
}

\author{
Samaneh Esfandiarpour \\ University of Kentucky, samaneh.esfandiarpour@uky.edu \\ Lindsay Boehme \\ PowerTech Water, LLC \\ J. Todd Hastings \\ University of Kentucky, todd.hastings@uky.edu
}

Follow this and additional works at: https://uknowledge.uky.edu/ece_facpub

Part of the Electrical and Computer Engineering Commons, and the Nanoscience and Nanotechnology Commons

Right click to open a feedback form in a new tab to let us know how this document benefits you.

\section{Repository Citation}

Esfandiarpour, Samaneh; Boehme, Lindsay; and Hastings, J. Todd, "Focused Electron Beam Induced Deposition of Copper with High Resolution and Purity from Aqueous Solutions" (2017). Electrical and Computer Engineering Faculty Publications. 32.

https://uknowledge.uky.edu/ece_facpub/32

This Article is brought to you for free and open access by the Electrical and Computer Engineering at UKnowledge. It has been accepted for inclusion in Electrical and Computer Engineering Faculty Publications by an authorized administrator of UKnowledge. For more information, please contact UKnowledge@lsv.uky.edu. 


\title{
Focused Electron Beam Induced Deposition of Copper with High Resolution and Purity from Aqueous Solutions
}

\author{
Digital Object Identifier (DOI) \\ https://doi.org/10.1088/1361-6528/aa5a4a \\ Notes/Citation Information \\ Published in Nanotechnology, v. 28, no. 12, 125301, p. 1-14. \\ (C) 2017 IOP Publishing Ltd.
}

After a 12-month embargo period from the publication of the Version of Record of this article, everyone is permitted to use, copy, and redistribute this article for non-commercial purposes only, provided that they adhere to all the terms of the Creative Commons Attribution-NonCommercial-NoDerivs 3.0 Unported license: https://creativecommons.org/licences/by-nc-nd/3.0

The document available for download is the authors' post-peer-review final draft of the article. 


\section{PAPER}

\section{Focused electron beam induced deposition of copper with high resolution and purity from aqueous solutions}

To cite this article: Samaneh Esfandiarpour et al 2017 Nanotechnology 28125301

\section{Manuscript version: Accepted Manuscript}

Accepted Manuscript is "the version of the article accepted for publication including all changes made as a result of the peer review process, and which may also include the addition to the article by IOP Publishing of a header, an article ID, a cover sheet and/or an 'Accepted Manuscript' watermark, but excluding any other editing, typesetting or other changes made by IOP Publishing and/or its licensors"

This Accepted Manuscript is (c) (c) 2017 IOP Publishing Ltd.

During the embargo period (the 12 month period from the publication of the Version of Record of this article), the Accepted Manuscript is fully protected by copyright and cannot be reused or reposted elsewhere.

As the Version of Record of this article is going to be / has been published on a subscription basis, this Accepted Manuscript is available for reuse under a CC BY-NC-ND 3.0 licence after the 12 month embargo period.

After the embargo period, everyone is permitted to use copy and redistribute this article for non-commercial purposes only, provided that they adhere to all the terms of the licence https://creativecommons.org/licences/by-nc-nd/3.0

Although reasonable endeavours have been taken to obtain all necessary permissions from third parties to include their copyrighted content within this article, their full citation and copyright line may not be present in this Accepted Manuscript version. Before using any content from this article, please refer to the Version of Record on IOPscience once published for full citation and copyright details, as permissions will likely be required. All third party content is fully copyright protected, unless specifically stated otherwise in the figure caption in the Version of Record.

View the article online for updates and enhancements. 


\title{
Focused Electron Beam Induced Deposition of
}

\section{Copper with High Resolution and Purity from}

\section{Aqueous Solutions}

\author{
Samaneh Esfandiarpour, ${ }^{\ddagger}$ Lindsay Boehme, ${ }^{\ddagger \dagger}$ and J. Todd Hastings ${ }^{*}$
}

Electrical and Computer Engineering, University of Kentucky, Lexington, KY 40506

\begin{abstract}
Electron-beam induced deposition of high-purity copper nanostructures is desirable for nanoscale rapid prototyping, interconnection of chemically synthesized structures, and integrated circuit editing. However, metalorganic, gas-phase precursors for copper introduce high levels of carbon contamination. Here we demonstrate electron beam induced deposition of highpurity copper nanostructures from aqueous solutions of copper sulfate. The addition of sulfuric acid eliminates oxygen contamination from the deposit and produces a deposit with $\sim 95$ at. $\%$ copper. The addition of sodium dodecyl sulfate (SDS), Triton X-100, or polyethylene glycole (PEG) improves pattern resolution and controls deposit morphology but leads to slightly reduced purity. High resolution nested lines with a $100 \mathrm{~nm}$ pitch are obtained from $\mathrm{CuSO}_{4}-\mathrm{H}_{2} \mathrm{SO}_{4}-\mathrm{SDS}-$

\footnotetext{
$\$$ These authors contributed equally

† Currently at PowerTech Water, LLC, 145 Graham Ave, ASTeCC A205, Lexington, KY 40506

* Corresponding Author, E-mail: todd.hastings@uky.edu
} 
$\mathrm{H}_{2} \mathrm{O}$. Higher aspect ratios $(\sim 1: 1)$ with reduced line edge roughness and unintended deposition are obtained from $\mathrm{CuSO}_{4}-\mathrm{H}_{2} \mathrm{SO}_{4}-\mathrm{PEG}-\mathrm{H}_{2} \mathrm{O}$. Evidence for radiation-chemical deposition mechanisms was observed, including deposition efficiency as high as 1.4 primary electrons $/ \mathrm{Cu}$ atom.

KEYWORDS: electron beam induced process, liquid phase, copper deposition, FEBID, direct write nanofabrication.

\section{INTRODUCTION}

Focused electron-beam induced deposition (FEBID) is a nano-scale patterning technique that allows the direct deposition of functional materials. This process has a variety of applications such as nano-scale rapid prototyping, lithographic mask and imprint template repair, interconnection to chemically synthesized nanostructures, and integrated circuit editing. Liquid-phase processes, in which deposition occurs at the interface between a substrate and a bulk liquid, are being investigated because they have potential for higher purity deposits, simpler precursors, access to new materials and faster processing rates. To date, $\mathrm{Pt}^{1-3}, \mathrm{Au}^{4}, \mathrm{Ag}^{5-7}, \mathrm{Pd}^{8}$ bimetallic alloys ( $\mathrm{AuAg}$ and $\mathrm{AuPt})^{9}$, semiconductors $(\mathrm{CdS})^{10}$ and $\mathrm{Cu}^{11-12}$ have been successfully deposited in sealed liquid cells. Recently, liquid-phase FEBID (LP-FEBID) on bulk substrates without liquid cells was accomplished using in-situ injection, ${ }^{7,13}$ environmental SEM (ESEM), or a combination of the two. ${ }^{14}$ Growth rates $10^{5}$ times greater than standard gas-phase FEBID were reported for carbon deposition from a liquid phase process by Fisher et al. ${ }^{7}$ However, there are challenges with this technique, such as the possibility of reactions in the bulk liquid, unintended deposition around the intended pattern, and liquid layer manipulation and control. 
Due to its high electrical conductivity, copper is the primary material used to form the complex network of interconnects that provide the electrical wiring on an integrated circuit. Copper interconnects continue to shrink in size due to the miniaturization of the transistor; as a consequence, circuit edit and debugging are being implemented at the nano-scale. The ability to both etch and deposit high purity copper with an e-beam could provide a powerful tool for this purpose. EBID of copper was first demonstrated with gaseous organometallic precursors that introduced a large amount of impurities, primarily carbon, into the deposit. ${ }^{15-17}$ Contaminant incorporation in copper can result in impaired grain growth, ${ }^{18}$ accelerated electromigration failure, ${ }^{19}$ and poor conductivity ${ }^{20-21}$, all of which are detrimental for the microelectronics industry. Deposition from liquid precursors promises potential solutions to these issues.

Liquid-phase FEBID of copper has been recently demonstrated on bulk substrates using in-situ hydration of solid precursors in an ESEM ${ }^{14}$ and using a capillary-style liquid injection system. ${ }^{13}$ In both cases, aqueous solutions of copper sulfate served as the precursor. In the ESEM effort, a surfactant, sodium dodecyl sulfate, was added to the precursor solution to thin and stabilize the liquid film to obtain higher resolution. Significant oxygen contamination was observed in both cases, qualitatively by Randolph et al. ${ }^{13}$ and estimated at $16-19$ at. $\%$ by Bresin et al. ${ }^{14}$ In the latter case sub-100 nm features were patterned, but no attempt was made to optimize the process for high resolution. Finally, unintended deposition, along with residue and precipitates, were often observed near the exposed patterns, and maintaining a stable, thin liquid layer through which one could pattern was challenging. Nevertheless, some preliminary measurements indicate that the resistivity of copper deposited from these solutions can be orders of magnitude lower than that deposited by gas-phase processes. ${ }^{22}$ 
The goal of this work was to improve the resolution and purity of copper FEBID from liquids while reducing unintended deposition and avoiding precipitation of undesired products. Figure 1 illustrates the deposition process used in this work in which the electron-beam reaches the substrate through a thin liquid layer and induces deposition at the interface. We hypothesized that the addition of sulfuric acid would reduce oxygen contamination by limiting copper oxides and hydroxides in the deposit. In addition, we expected both sulfuric acid and surfactants would improve pattern fidelity by reducing contact angles and stabilizing thin liquid films. Furthermore, additives common to electroplating baths should improve pattern fidelity by reducing grain size and by suppressing unintended deposition around the pattern. Finally, we anticipated that the low concentrations of organic additives would only slightly reduce the purity of the deposits. We found that these hypotheses were confirmed with varying degrees of quantitative improvement.
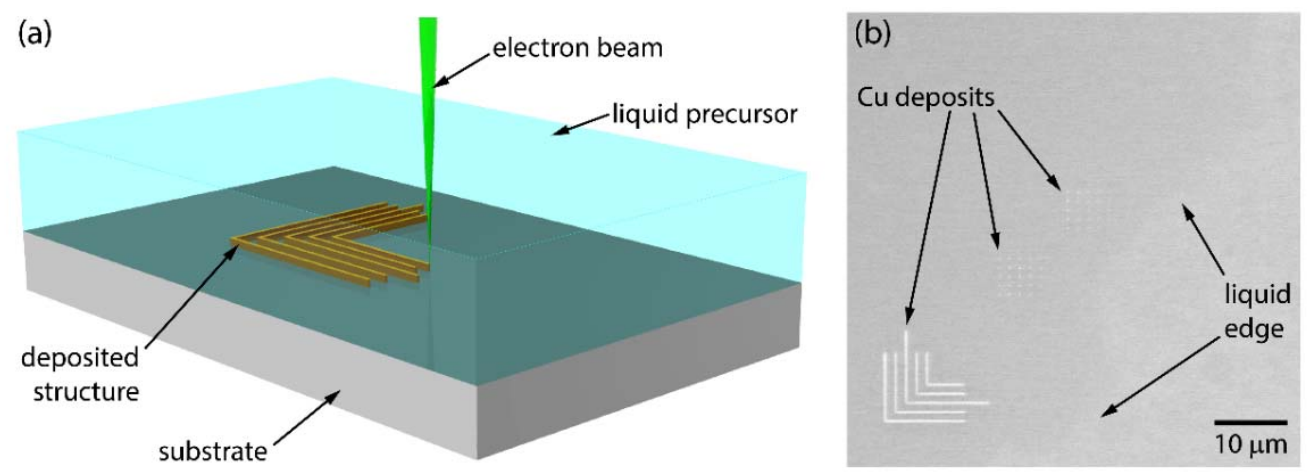

Figure 1. (a) Schematic of LP-FEBID of copper. An aqueous solution containing copper sulfate serves as the precursor and remains liquid in an environmental SEM. The electronbeam drives the deposition reaction at the substrate-liquid interface. (b) In-situ electron micrograph showing the liquid edge with deposited copper patterns. The liquid covered region is darker. 


\section{METHODS}

All experiments were carried out in a Quanta 250 FEG environmental scanning electron microscope (ESEM, FEI Co., Hillsboro, OR, USA) at an accelerating voltage of $30 \mathrm{kV}$. Three different substrates were used: (1) a silicon substrate with a sputter deposited copper coating and polymer liquid wells, (2) a silicon substrate with a $1 \mu \mathrm{m}$ thick electrodeposited copper film on a $\mathrm{Mn} / \mathrm{Cu}-\mathrm{Ta}-\mathrm{TaN}$ barrier layer, and (3) a silicon substrate with a sputter deposited chromium coating. The sputtered coatings, both approximately $30 \mathrm{~nm}$ thick, improved adhesion of the deposits. The liquid wells were created using photolithography and SU-8 resist (Microchem Inc.). The SU-8 layer was $100 \mu \mathrm{m}$ thick and the substrate was n-type silicon. The precursor was loaded into the well ex-situ as a dilute solution, dehydrated during ESEM pump down, and then rehydrated by control of water vapor pressure and substrate temperature. A liquid meniscus forms in the well with a thin central region in which high-resolution patterning can be conducted.

Substrates were oxygen plasma cleaned before each experiment and a Peltier stage was used to maintain their temperature during FEBID. Conductive silver paint (SPI Supplies) was used to attach the substrate to the sample mount. The precursor copper solution contained $\mathrm{CuSO}_{4}: 5 \mathrm{H}_{2} \mathrm{O}$ (Fisher Scientific) in deionized water (DI $\mathrm{H}_{2} \mathrm{O}$ ). The solubility of copper sulfate at the temperatures of interest is $0.9 \mathrm{M},{ }^{23}$ but is reduced somewhat by the addition of sulfuric acid. ${ }^{24}$ The concentration of $\mathrm{CuSO}_{4}$ was initially chosen as $0.5 \mathrm{M}$ to maximize the $\mathrm{Cu}^{2+}$ concentration without saturating the solution, but in most experiments it was reduced to $0.25 \mathrm{M}$ to reduce unintended deposition as discussed in Section 3. Different solution compositions were studied; this included the addition of $\mathrm{H}_{2} \mathrm{SO}_{4}$ (EMD Millipore), surfactants, and plating additives, individually or in combination. Surfactants tested included: sodium dodecyl sulfate (SDS, Acros Organics) and Triton X-100 (Sigma-Aldrich). SDS was selected to test the effect of an anionic 
surfactant, while Triton X-100 was selected to test the effect of a non-ionic surfactant. Additives tested included: $\mathrm{Cl}^{-}(\mathrm{KCl}$, Fisher Scientific), polyethylene glycol with a molecular weight of 1000 (PEG 1000, VWR), and bis-(3-sulfopropyl) disulfide (SPS, Combi-Blocks).

Prior to deposition, the substrate temperature was set to $3^{\circ} \mathrm{C}$, a drop of the precursor copper solution was placed on the substrate (volumes noted in discussion), and the chamber was pumped to an initial pressure of 5.5 torr. At these conditions the precursor solution dehydrates to form either a solid, in the absence of $\mathrm{H}_{2} \mathrm{SO}_{4}$, or a viscous liquid, in the presence of $\mathrm{H}_{2} \mathrm{SO}_{4}$. By slowly increasing the water vapor pressure in the chamber to $\sim 6$ torr while maintaining the substrate temperature, the precursor rehydrates. The pressure can then be further adjusted to stabilize the droplet and establish a thin liquid edge for patterning.

Patterns were deposited using a Raith Elphy Plus electron beam lithography attachment and a fast beam blanker. The beam current was measured with a Faraday cup and Keithley 6487 picoammeter before each experiment. The beam current was between 365 and $386 \mathrm{pA}$ for all experiments on the electrodeposited copper substrate. Patterns were deposited in the microwells at a beam current of $490 \mathrm{pA}$. Several patterns were used to test each solution: $100 \mathrm{~nm}, 200 \mathrm{~nm}$, and 1 and $1.5 \mu \mathrm{m}$ pitch nested lines with a linear dose of 5 to $30 \mu \mathrm{C} / \mathrm{cm}$, dot arrays of $4 \times 4$ elements and $1 \mu \mathrm{m}$ spacing with a dot dose of $100 \mathrm{pC}$, and $5 \times 5$ elements and 1 or $1.5 \mu \mathrm{m}$ spacing with a dot dose of 100 to $1000 \mathrm{pC}$. Deposition efficiency was calculated from cross-sectional area estimates. Line widths were determined from top down SEM images by averaging over a $3 \mu \mathrm{m}$ long segment that starts just inside the nested-L structure. Heights were determined from the same area using $60^{\circ}$ tilt images. ImageJ was used for image calibrations and measurements. 


\section{RESULTS AND DISCUSSION}

\subsection{Copper Deposition from $\mathrm{CuSO}_{4}$ and surfactants in microwells.}

Sodium dodecyl sulfate (SDS) is a widely used anionic surfactant which will reduce the liquid contact angle with the substrate. Depositing copper in the thinner edge region of a droplet containing $\mathrm{CuSO}_{4}$ and $\mathrm{SDS}$ improved pattern resolution compared to patterning in solutions containing only $\mathrm{CuSO}_{4}{ }^{14}$ However, controlling the spreading of the droplet containing the surfactant can be challenging; thus, it is convenient to add microwells to the substrate to constrain the droplet as shown in Figure 2. These wells also allow different liquid precursors to be dispensed on the same substrate because hydration/condensation only occurs inside the wells and not on the top surface of the well material (SU-8 resist in this case).
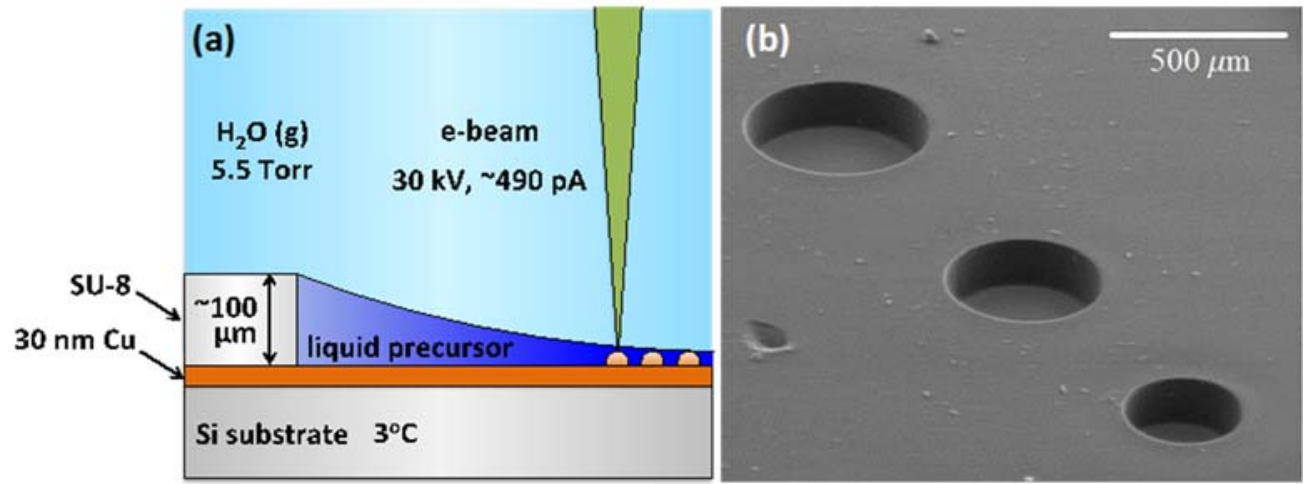

Figure 2. (a) Schematic illustration of copper deposition from a liquid precursor in a microwell. (b) $50^{\circ}$ tilt-view of SU-8 microwells with different diameters on a silicon substrate.

Figure 3 shows $400 \mathrm{~nm}$ pitch nested lines deposited from an aqueous solution of $\mathrm{CuSO}_{4}$ and SDS, with initial concentrations of $0.25 \mathrm{M}$ and $4 \mathrm{mM}$, respectively, in a $400-\mu \mathrm{m}$ diameter well. The precursor was dehydrated on pump down and rehydrated in the ESEM chamber. There was some unintended deposition close to the patterning region. Moreover, precipitation of other solids was observed during the patterning process which is not surprising given the composition of the 
solution and the experimental conditions. First, the temperature used for LP-FEBID is below the Krafft point for SDS $\left(10^{\circ} \mathrm{C}\right),{ }^{25-27}$ such that micelles no longer form. Instead, if the concentration increases above the critical micelle concentration $(\sim 8 \mathrm{mM}$ and only weakly dependent on temperature $)^{28}$ then SDS will precipitate as crystals. Secondly, $\mathrm{CuSO}_{4}$ will slowly react with SDS to form $\mathrm{Cu}(\mathrm{DS})_{2}$ which is essentially insoluble at the temperatures used here. ${ }^{29}$

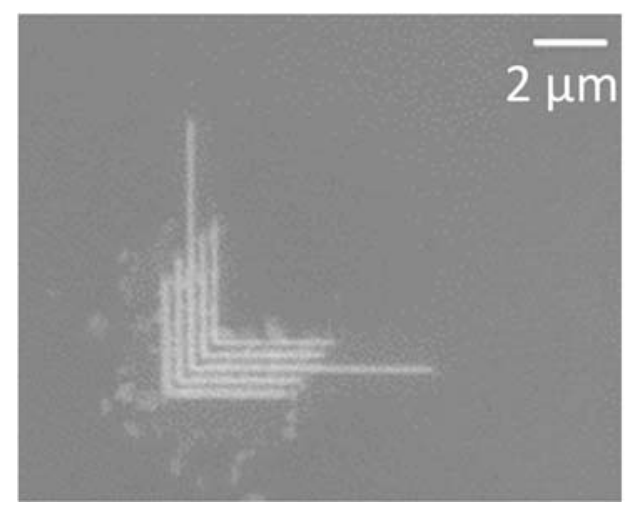

Figure 3. $400 \mathrm{~nm}$ pitch nested lines deposited in a micro-well from an aqueous solution with initial concentration of $0.25 \mathrm{M} \mathrm{CuSO}_{4}$ and $4 \mathrm{mM} \mathrm{SDS}$ and a linear dose of $40 \mu \mathrm{C} / \mathrm{cm}$.

Energy dispersive x-ray spectroscopy (EDX) measurements of these patterns showed carbon, oxygen, and sulfur peaks in addition to copper. Sulfur is either incorporated during deposition from the decomposition of SDS or stems from residual SDS or $\mathrm{Cu}(\mathrm{DS})_{2}$ near the pattern. The concentrations were not quantifiable because of the proximity to the SU-8 well structure which contributed to the $\mathrm{C}$ and $\mathrm{O}$ signals and charged during the measurement. Thus, although SDS enables reasonably high resolution patterning, it appears to be a sub-optimal choice for copper FEBID under ESEM conditions.

To avoid problems associated with precipitation and reaction of SDS, it was replaced by Triton $\mathrm{X}-100$. Triton $\mathrm{X}-100$ is a common non-ionic surfactant which does not precipitate at low temperatures in aqueous solutions. Instead, lower operational temperatures are limited by freezing. ${ }^{27}$ In addition, Triton X-100 does not phase separate until it reaches its cloud point at 
approximately $65^{\circ} \mathrm{C}$. This broad range of working temperatures seems ideal for LP-FEBID. Figure 4(a) shows $1 \mu \mathrm{m}$ pitch nested lines deposited from a solution with an initial concentration of $0.5 \mathrm{M} \mathrm{CuSO}_{4}$ and $0.5 \mathrm{mM}$ Triton $\mathrm{X}-100$ at a dose of $40 \mu \mathrm{C} / \mathrm{cm}$. Unwanted deposition and residues are visible surrounding the nested lines. The unwanted copper deposition was reduced when the initial concentration of $\mathrm{CuSO}_{4}$ was decreased to $0.25 \mathrm{M}$ (Figure 4(b)).

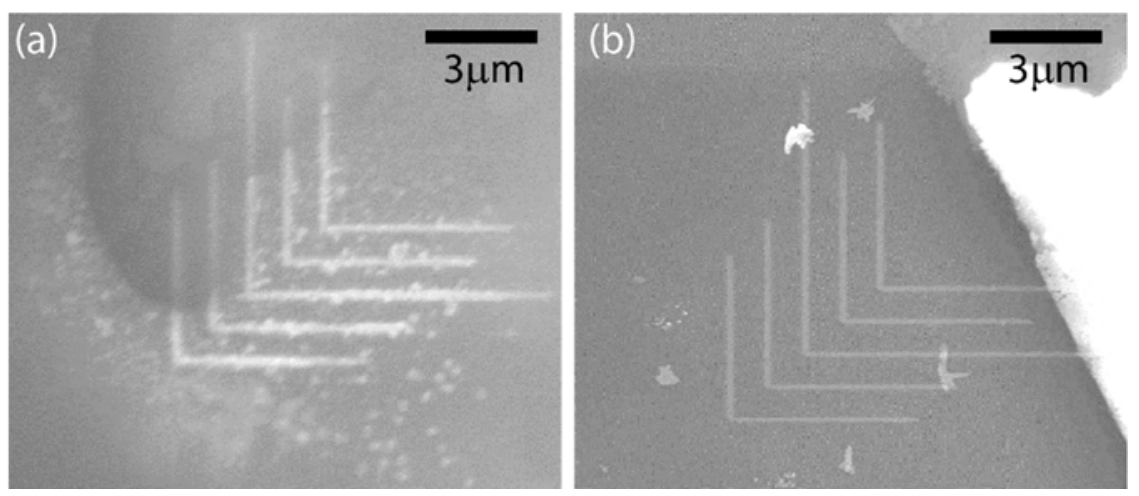

Figure 4. Patterns deposited in microwells from an aqueous solution of $\mathrm{CuSO}_{4}$ and Triton $\mathrm{X}-100.1 \mu \mathrm{m}$ nested lines were deposited at a dose of $40 \mu \mathrm{C} / \mathrm{cm}$ from a solution with initial concentrations of (a) $0.5 \mathrm{M} \mathrm{CuSO}_{4}$ and $0.5 \mathrm{mM}$ Triton X-100 and (b) $0.25 \mathrm{M} \mathrm{CuSO}_{4}$ and $0.5 \mathrm{mM}$ Triton X-100. Surfactant residue is visible in both images as dark regions covering the lines, and in (b) as a large, bright charged region on the right. Unintended copper deposition can be seen as bright spots in (a). Contrast and brightness were adjusted to make the various features as visible as possible.

Nevertheless, difficult to remove residues can also be seen in both experiments. One possible explanation for this is that Triton X-100 also has a hexagonal phase that can form an insoluble gel at high concentrations, even at room temperature. ${ }^{31}$ Although this is reversible on heating in the presence of water, it is not likely to dissolve under the dehydrated and cooled ESEM conditions. Thus, Triton X-100- $\mathrm{CuSO}_{4}-\mathrm{H}_{2} \mathrm{O}$ solutions can only be used if the concentration is not allowed to enter the critical gel concentration range while in the ESEM, even during pump down. This can 
prove challenging in the dynamic pressure environment of the ESEM. EDX measurements of these patterns revealed that there was no sulfur contamination after the replacement of SDS with Triton; however, significant oxygen content remained. Again, quantification was not possible for the small patterns in the microwells. Triton appears advantageous for avoiding precipitation and sulfur contamination, and conditions were found that produced little unwanted copper deposition. However, difficulties avoiding residue formation and continuing oxygen incorporation motivated a search for a further improved precursor solution.

\subsection{Copper deposition from $\mathrm{CuSO}_{4}$ and $\mathrm{H}_{2} \mathrm{SO}_{4}$}

Sulfuric acid is a promising liquid reactant for use in reduced pressure environments such as an ESEM. First, it has a low vapor pressure of $10^{-3} \mathrm{~Pa},{ }^{32}$ and has been used successfully under vacuum in an Auger spectroscopy system. ${ }^{33}$ Secondly, the freezing point of the $\mathrm{H}_{2} \mathrm{SO}_{4}-\mathrm{H}_{2} \mathrm{O}$ system falls rapidly toward $210 \mathrm{~K}$ as the $\mathrm{H}_{2} \mathrm{SO}_{4}$ concentration increases toward $5 \mathrm{M}^{34}$ Likewise, concentration of the precursor can be controlled/estimated based on equilibrium with water vapor. ${ }^{35}$ Previously, we exploited these properties to demonstrate electron beam induced etching (EBIE) of copper using $\mathrm{H}_{2} \mathrm{SO}_{4} .{ }^{36}$

Sulfuric acid is also a promising addition to solutions for liquid phase FEBID of $\mathrm{Cu}$ for several reasons. First, $\mathrm{CuSO}_{4}-\mathrm{H}_{2} \mathrm{SO}_{4}-\mathrm{H}_{2} \mathrm{O}$ is perhaps the most common system for copper electrodeposition and there is extensive guidance in the literature for choosing additives to control the morphology of the deposits. Secondly, $\mathrm{CuSO}_{4}$ hydrates and precipitates rather abruptly as temperature falls and/or water vapor pressure rises. In contrast, sulfuric acid solutions remain liquid under most ESEM conditions and allow more gradual hydration/dehydration. Third, sulfuric acid reduces surface tension to improve wetting of the substrate and thin the liquid edge. 
Fourth, adding sulfuric acid to the copper precursor solution is expected to prevent formation of copper oxides and copper hydroxide.

Despite the convenience of constraining the liquid precursor in microwells, the complications arising from quantification of deposit composition and the sporadic observance of resist residue prompted us to choose a more controlled substrate for further study. More data is provided in the supplementary information. In order to eliminate concerns about adhesion, interfacial layers, and charging we chose to deposit copper on thick electroplated copper on a silicon wafer as shown in Figure 5.

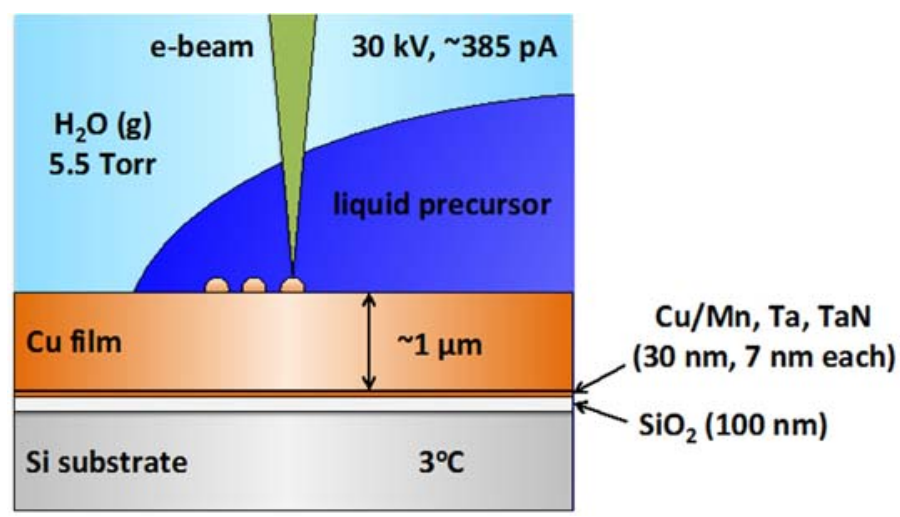

Figure 5. Schematic of the experimental set-up for LP-FEBID of copper on an electrodeposited copper film.

At the concentration of acidic precursor tested, decreasing the dose helps to obtain cleaner patterns. However, higher resolution lines (200 $\mathrm{nm}$ and $100 \mathrm{~nm}$ pitch nested lines) were difficult to deposit from the acidic solution and the lines merged even with low doses. This may have occurred due to the droplet contact angle being too large, and the liquid edge not thin and uniform enough, for the electron beam to pattern high resolution lines. The region for depositing patterns successfully is only a few microns. The effect of liquid thickness is demonstrated in Figure 6 by incomplete 1- $\mu \mathrm{m}$ pitch nested lines in panel (a) and an incomplete $4 \times 4$ dot array with different 
doses (200 pC, $300 \mathrm{pC}$ and $400 \mathrm{pC}$ from left to right) in panel (b). The desired pattern is missing close to the liquid edge due to the absence of the liquid, whereas, patterns were not deposited effectively in thicker liquid where the electron beam could not penetrate to the substrate.

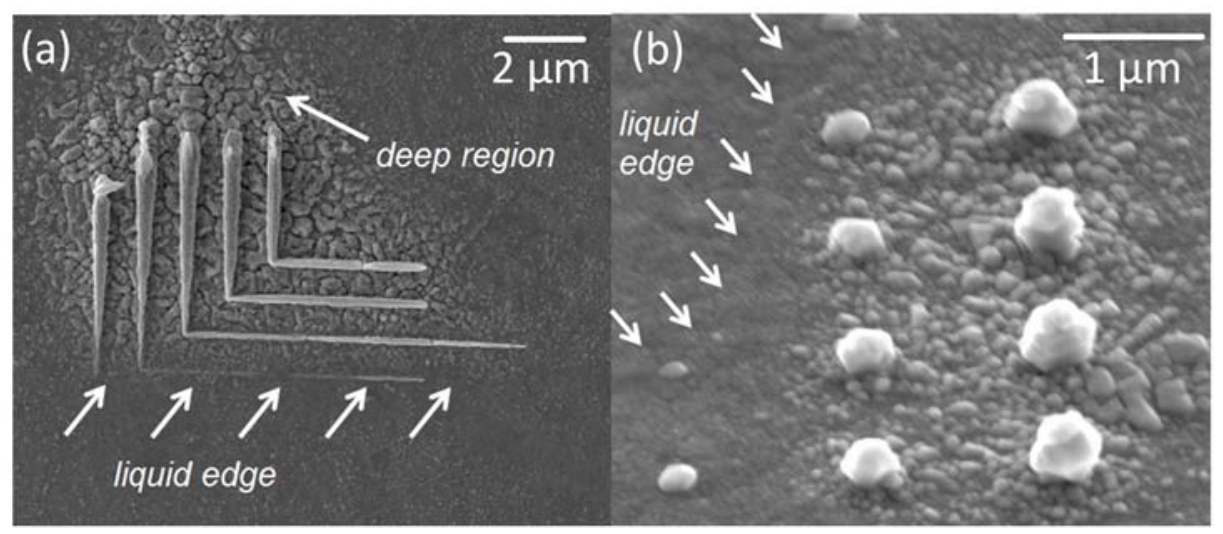

Figure 6. Incomplete patterns deposited from $0.25 \mathrm{M} \mathrm{CuSO}_{4}$ and $0.1 \mathrm{M} \mathrm{H}_{2} \mathrm{SO}_{4}$ : (a) $1 \mu \mathrm{m}$ pitch nested lines, (b) $45^{\circ}$ tilted view of dot patterns with $4 \times 4$ elements and $1 \mu \mathrm{m}$ pitch with increasing dose of $100 \mathrm{pC}$ per dot for the columns from left to right.

\subsection{Copper deposition from acidified $\mathrm{CuSO}_{4}$ and surfactants}

To overcome challenges associated with liquid thickness, surfactant was added to the precursor solution to reduce the interfacial energy. SDS was added to the solution described in the previous section and $0.25 \mu l$ of the new solution was dispensed onto the substrate. The substrate was then loaded into the ESEM with an initial temperature of $3^{\circ} \mathrm{C}$ and pressure of 5.5 torr. After adjusting the chamber pressure and stabilizing the liquid edges, several patterns were deposited successfully. Figure 7 presents nested lines with (a) $100 \mathrm{~nm}$ pitch, (b) $200 \mathrm{~nm}$ pitch, and (c) $1 \mu \mathrm{m}$ pitch deposited at a dose of $5 \mu \mathrm{C} / \mathrm{cm}$ from a $\mathrm{CuSO}_{4}, \mathrm{SDS}$, and $\mathrm{H}_{2} \mathrm{SO}_{4}$ solution on a copper substrate. Micrographs were taken $e x$-situ under high vacuum after rinsing the sample gently with DI-water. Addition of SDS to the acidified copper sulfate solution improved wetting behavior, providing a larger region 
on the substrate surface for patterning at the droplet edge. However, as discussed for $\mathrm{CuSO}_{4}$ and SDS, precipitation is seen in the background of the images.

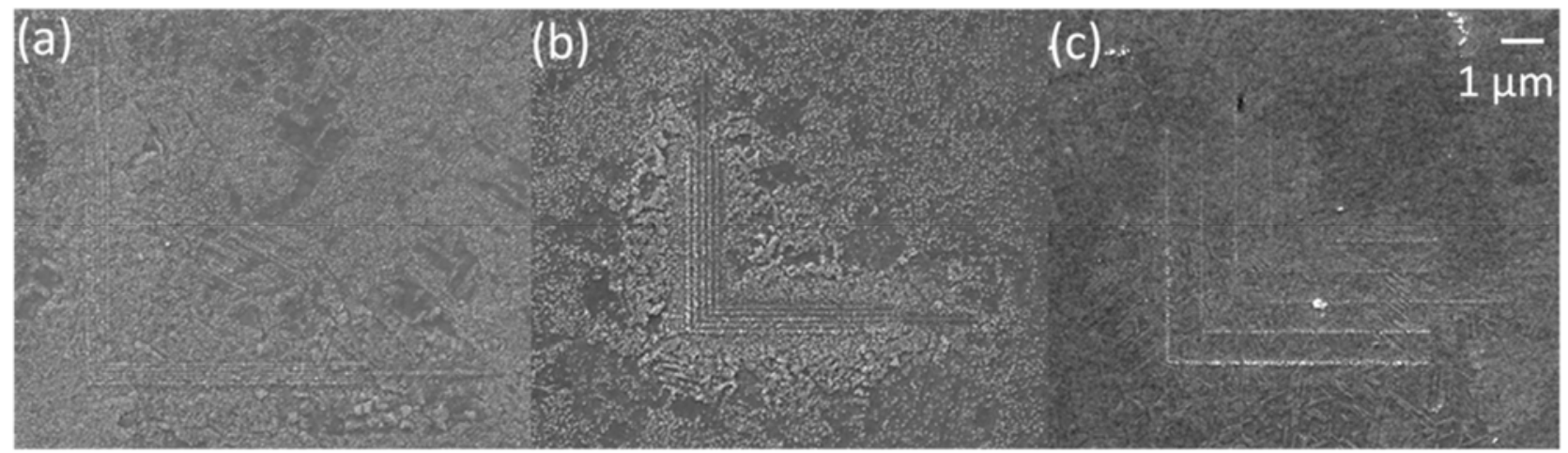

Figure 7. Nested lines with (a) $100 \mathrm{~nm}$ pitch, (b) $200 \mathrm{~nm}$ pitch, and (c) $1 \mu \mathrm{m}$ pitch with a dose of $5 \mu \mathrm{C} / \mathrm{cm}$ from $0.25 \mathrm{M} \mathrm{CuSO}_{4}, 1 \mathrm{mM} \mathrm{SDS}$, and $0.1 \mathrm{M} \mathrm{H}_{2} \mathrm{SO}_{4}$ on a copper substrate.

Triton X-100 is known to be soluble and stable in acidic solutions, so it was added to the acidified $\mathrm{CuSO}_{4}$ solution to reduce the contact angle and improve resolution while avoiding the precipitation and reactions present with SDS. Figure 8 shows $200 \mathrm{~nm}$ pitch nested lines with decreasing doses of (a) $20 \mu \mathrm{C} / \mathrm{cm}$, (b) $10 \mu \mathrm{C} / \mathrm{cm}$ and (c) $5 \mu \mathrm{C} / \mathrm{cm}$. Figure 9 displays a $60^{\circ}$ tilted view of 5 x 5 dot arrays with $1 \mu \mathrm{m}$ spacing. Here the dose effect is more easily observed - less copper is deposited at a lower dose. Unintended deposition between the elements decreases noticeably with dose from $1000 \mathrm{pC}$ in (a) to $500 \mathrm{pC}$ in (c). Moreover, the background is very clean compared to the previous precursor, SDS, which indicates that Triton X-100 is a better choice to improve the wetting process. Figure 8 and Figure 9 indicate that reducing the dose is likely lessening the unintended depositions close to the exposed region. 


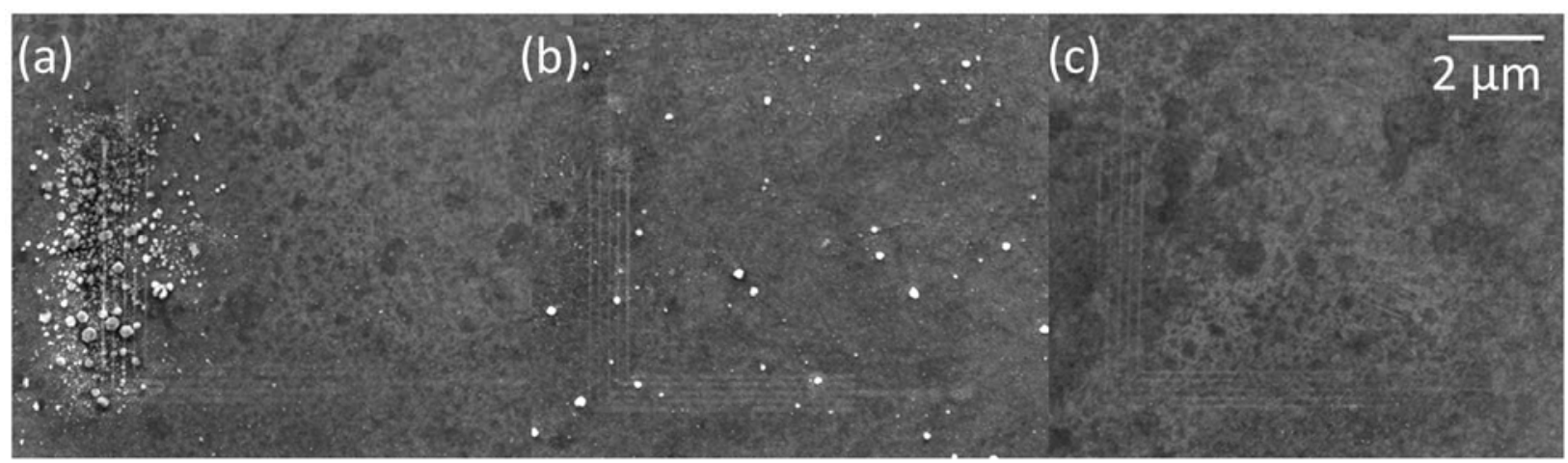

Figure 8. $200 \mathrm{~nm}$ pitch nested lines deposited from an aqueous solution of $0.25 \mathrm{M} \mathrm{CuSO}_{4}, 1$ mM Triton X-100, and $0.1 \mathrm{M} \mathrm{H}_{2} \mathrm{SO}_{4}$ at a dose of (a) $20 \mu \mathrm{C} / \mathrm{cm}$, (b) $10 \mu \mathrm{C} / \mathrm{cm}$, and (c) 5 $\mu \mathrm{C} / \mathrm{cm}$ on an electrodeposited copper film.

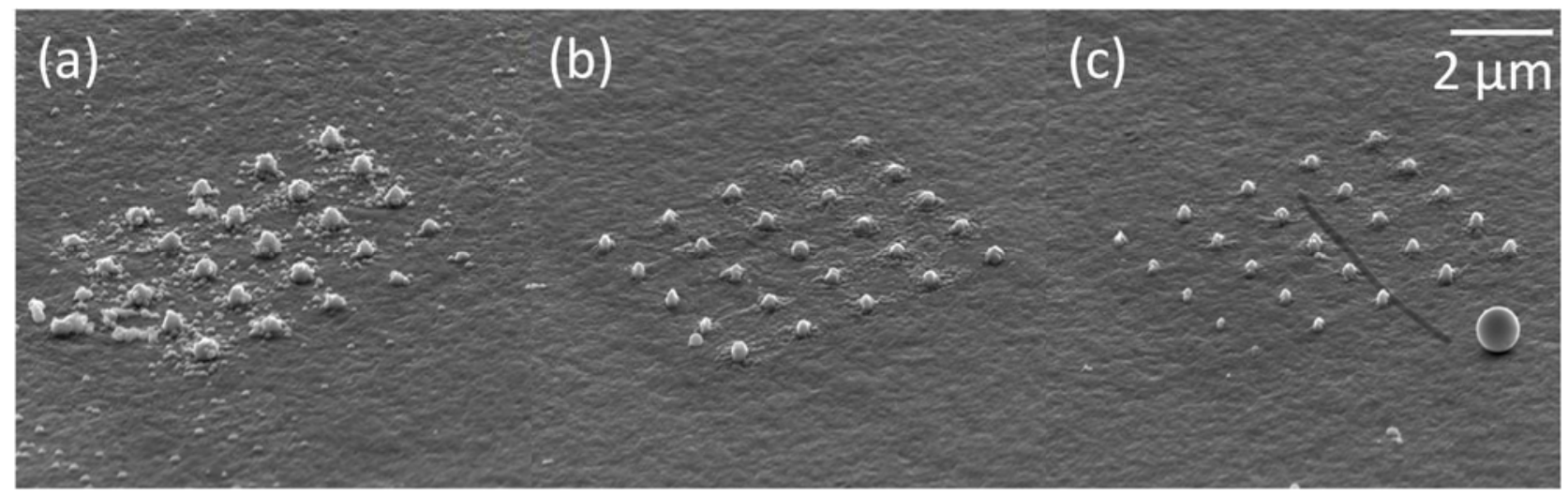

Figure $9.60^{\circ}$ tilt-view of dot arrays of $5 \times 5$ elements and $1 \mu \mathrm{m}$ spacing deposited from an aqueous solution of $0.25 \mathrm{M} \mathrm{CuSO}_{4}, 1 \mathrm{mM}$ Triton X-100, and $0.1 \mathrm{M} \mathrm{H}_{2} \mathrm{SO}_{4}$ at a dose of (a) $1000 \mathrm{pC}$, (b) $800 \mathrm{pC}$, and (c) $500 \mathrm{pC}$, per dot.

Figure 10 shows the reduction of unintended deposition by the addition of Triton $\mathrm{X}-100$ to the acidified copper precursor. Panel (a) is a magnified view of $1 \mu \mathrm{m}$ pitch nested lines deposited from $\mathrm{CuSO}_{4}-\mathrm{H}_{2} \mathrm{SO}_{4}$ without additives at a dose of $30 \mu \mathrm{C} / \mathrm{cm}$, panel (b) is the same pattern and dose after adding Triton $\mathrm{X}-100$, and panel (c) is $\mu \mathrm{m}$ pitch nested lines from a $\mathrm{CuSO}_{4}$, Triton $\mathrm{X}-100$, and $\mathrm{H}_{2} \mathrm{SO}_{4}$ precursor at a lower dose of $20 \mu \mathrm{C} / \mathrm{cm}$. The Triton $\mathrm{X}-100$ reduces grain size and deposition 
rate. It also appears to reduce, though certainly not eliminate, unwanted deposition around the desired patterns.

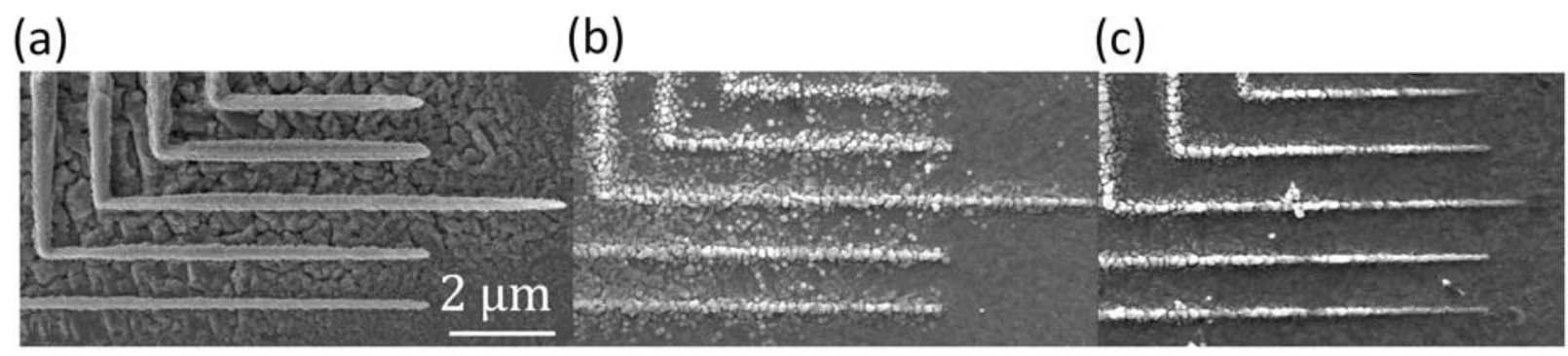

Figure 10. $1 \mu \mathrm{m}$ nested lines deposited from an aqueous solution of (a) $0.25 \mathrm{M} \mathrm{CuSO}_{4}$ and $0.1 \mathrm{M} \mathrm{H}_{2} \mathrm{SO}_{4}$ at a dose of $30 \mu \mathrm{C} / \mathrm{cm}$, (b) $0.25 \mathrm{M} \mathrm{CuSO}_{4}, 1 \mathrm{mM}$ Triton $\mathrm{X}-100$, and $0.1 \mathrm{M}$ $\mathrm{H}_{2} \mathrm{SO}_{4}$ at a dose of $30 \mu \mathrm{C} / \mathrm{cm}$, (c) $0.25 \mathrm{M} \mathrm{CuSO}_{4}, 1 \mathrm{mM}$ Triton X-100, and $0.1 \mathrm{M} \mathrm{H}_{2} \mathrm{SO}_{4}$ at a dose of $20 \mu \mathrm{C} / \mathrm{cm}$ on an electrodeposited copper film.

\subsection{Copper Deposition with Plating Additives}

Another approach to improve deposition was to borrow chemistries associated with electroplating or electrodeposition. Copper electrodeposition is widely used in the microelectronics industry for the fabrication of printed circuit boards (PCB) and interconnect metallization. The miniaturization of microelectronic devices poses a challenge for copper electrodeposition. In order to enable void-free fill of small features with high aspect ratios, special plating additives are required. Copper is electrodeposited from an acidic copper sulfate electrolyte containing a suppressor, typically a polyether such as polyethylene glycol (PEG), an antisuppressor or accelerator, which is a sulfur-containing molecule such as bis-(3-sulfopropyl) disulfide (SPS), and a chloride ion. ${ }^{37-38}$ Suppressors adsorb to the copper substrate and inhibit deposition, while anti-suppressors have the opposite effect and promote copper deposition. Antisuppressors are also referred to as brighteners because they act to refine the copper grain 
structure. ${ }^{39}$ The additive distribution within a feature controls the local plating rates to prevent defects from forming.

By taking advantage of the inhibiting property of a suppressor and adding it to the copper precursor solution, we hoped to prevent unwanted deposition surrounding the exposed patterns. Additive selection was based on organic molecules used for the metallization of nano-scale features: the most commonly used suppressor, PEG, and anti-suppressor, SPS. Figure 11 shows copper deposition results for all additive combinations tested at a line dose of $30 \mu \mathrm{C} / \mathrm{cm}$. In the presence of PEG with $\mathrm{Cl}^{-}$, copper deposition is inhibited; similar to what is expected in electrodeposition. In the presence of chloride ion, suppressors will adsorb more strongly to the substrate and inhibit deposition more effectively. ${ }^{40}$ The tilted micrographs in Figure 12 show the influence of PEG and $\mathrm{Cl}^{-}$on copper deposition more clearly. At the same line dose, the height of the line deposited with no additives, $\mathrm{PEG}$, and PEG with $\mathrm{Cl}^{-}$was approximately $390 \mathrm{~nm}, 230 \mathrm{~nm}$, and $95 \mathrm{~nm}$, respectively. Visibly PEG suppresses copper deposition, and is even more effective at doing so with the addition of $\mathrm{Cl}^{-}$. When SPS is added, the copper lines become more granular in appearance and there are more precipitates that adhere to the substrate that cannot be rinsed away. In the presence of all 3 additives $\left(\mathrm{Cl}^{-}, \mathrm{PEG}\right.$, and SPS), precipitation of salts or other compounds is exacerbated. SPS does not work well at the conditions tested and is unsuitable for FEBID of copper. The best resolution was obtained with the acidified copper sulfate solution in the presence of PEG. 

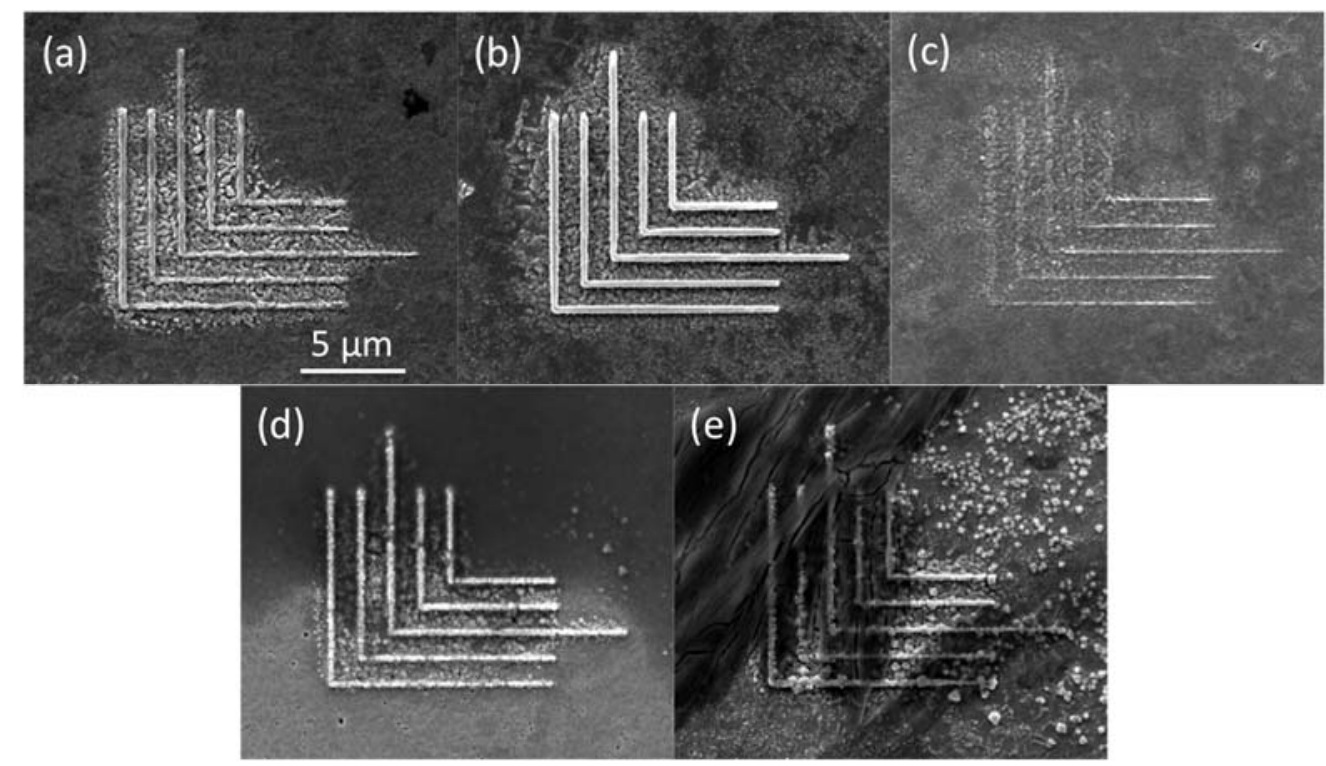

Figure 11. $1.5 \mu \mathrm{m}$ pitch nested lines deposited from an acidified copper sulfate solution at a line dose of $30 \mu \mathrm{C} / \mathrm{cm}$ with the addition of different plating additives: (a) no additives, (b) 100 ppm PEG 1000, (c) 50 ppm Cl- and 100 ppm PEG 1000, (d) 50 ppm SPS, and (e) 50 ppm Cl-, 100 ppm PEG 1000, and 50 ppm SPS. The best resolution is obtained in the presence of PEG, panel (b).

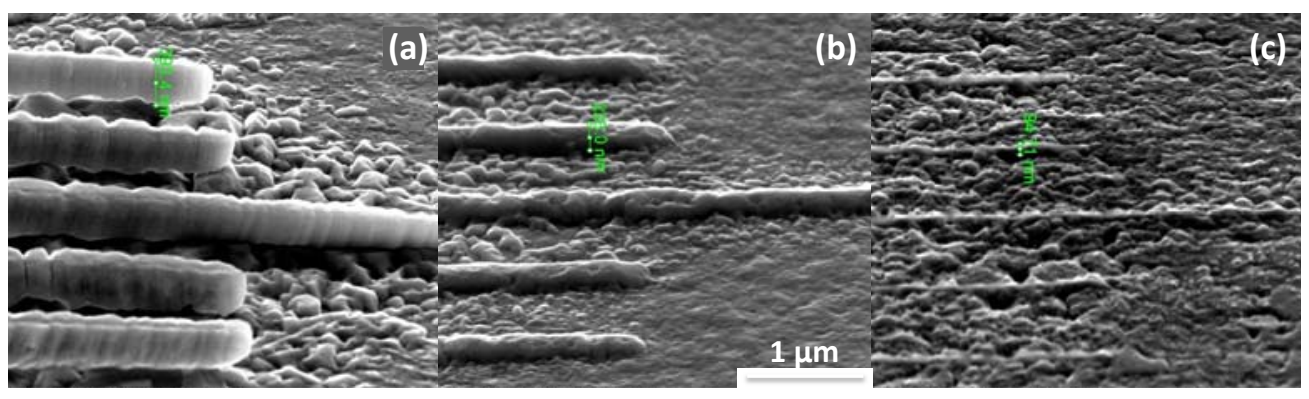

Figure 12. $1.5 \mu \mathrm{m}$ pitch nested lines deposited from an acidified copper sulfate solution at a line dose of $30 \mu \mathrm{C} / \mathrm{cm}$ with the addition of different plating additives: (a) no additives, (b) 100 ppm PEG 1000, and (c) 50 ppm Cl- and 100 ppm PEG 1000. Copper deposition is suppressed in the presence of PEG, and even further with the addition of Cl-. 
Figure 13 and Figure 14 show the effect of dose on $1.5-\mu \mathrm{m}$ pitch nested lines for the acidified copper sulfate solution in the absence and presence of PEG, respectively. Both sets of data give similar results - thinner lines and less unintended deposition is observed at lower doses. The cleanest patterns are obtained at a dose of $5 \mu \mathrm{C} / \mathrm{cm}$. At a dose below $5 \mu \mathrm{C} / \mathrm{cm}$ no deposition is visible. In Figure 15 we plot the estimated cross-sectional area of the primary deposit (excluding unintended deposition) vs. linear dose with and without PEG. The error bars represent the intraexperimental spread of the five line widths and account for proximity effects and liquid thickness variations. The error bars do not capture inter-experimental sources of error and this may explain the anomalously high cross-sectional area in the presence of PEG at $10 \mu \mathrm{C} / \mathrm{cm}$ period Regardless, as the dose increases the suppressive effect of PEG becomes clear. In addition, PEG markedly reduces the variation in linewidth, presumably because it creates a more uniform liquid layer and finer grained deposits. This effect is also qualitatively visible in Figure 14.

The relative uniformity of the unintended deposition in Figures 13 and 14 provides the opportunity to assess the range of this effect. We observe that the range is approximately $1 \mu \mathrm{m}$ which is consistent with the backscattered electron range at the surface of a silicon substrate with a $1 \mu \mathrm{m}$ thick copper film. Detailed description on the backscattered electron range is available in the supplementary document.

Finally, we can place approximate bounds on the efficiency of the deposition process. Based on the measurements from Figure 15, we can estimate the deposition efficiency in terms of $\mathrm{Cu}$ atoms deposited per primary electron. For the highest dose without PEG we find that approximately 1.4 primary electrons are required for each copper atom deposited. For the lowest dose, for which both solutions are similar, we find that 3.3 primary electrons per $\mathrm{Cu}$ atom are necessary. These numbers pertain only to the primary deposit, and the total efficiency will be higher if one includes 
unintended deposition. The increase in efficiency at high doses in the absence of PEG is surprising as one would expect either linear growth or sub-linear growth depending on whether significant depletion of $\mathrm{Cu}^{2+}$ was occurring. Regardless, these efficiencies are markedly higher than $\mathrm{Cu}$ deposition from gas-phase metalorganic precursors. For example, when using copper(II) hexafluoroacetylacetonate, $\sim 10$ primary electrons are required for each deposited atom in the matrix (90 at.\% carbon) and $\sim 100$ primary electrons required for each copper atom. ${ }^{34}$

Figure 16 shows the effect of dose and refresh time on $1.5 \mu \mathrm{m}$ pitch $5 \times 5$ dot arrays from the same solution described above. As anticipated, more copper is deposited at a higher dose. Smaller copper dots are observed at $100 \mathrm{pC}$ than $1000 \mathrm{pC}$, Figure 16 (a) and (b), respectively. To check if refresh time affects liquid-phase FEBID of copper, the dot array was deposited with a dose of 100 $\mathrm{pC}$ and pulsed 10 times to give a total dose of $1000 \mathrm{pC}$. A refresh time of $100 \mathrm{~ms}$ was added between each pulse. Comparing experiments with and without added refresh time, Figure 16 (c) and (b), respectively, there is little to no difference. Refresh time does not appear to have an effect on the FEBID of copper from these solutions, suggesting that no significant depletion of $\mathrm{Cu}^{2+}$ is occurring under the conditions investigated here. 


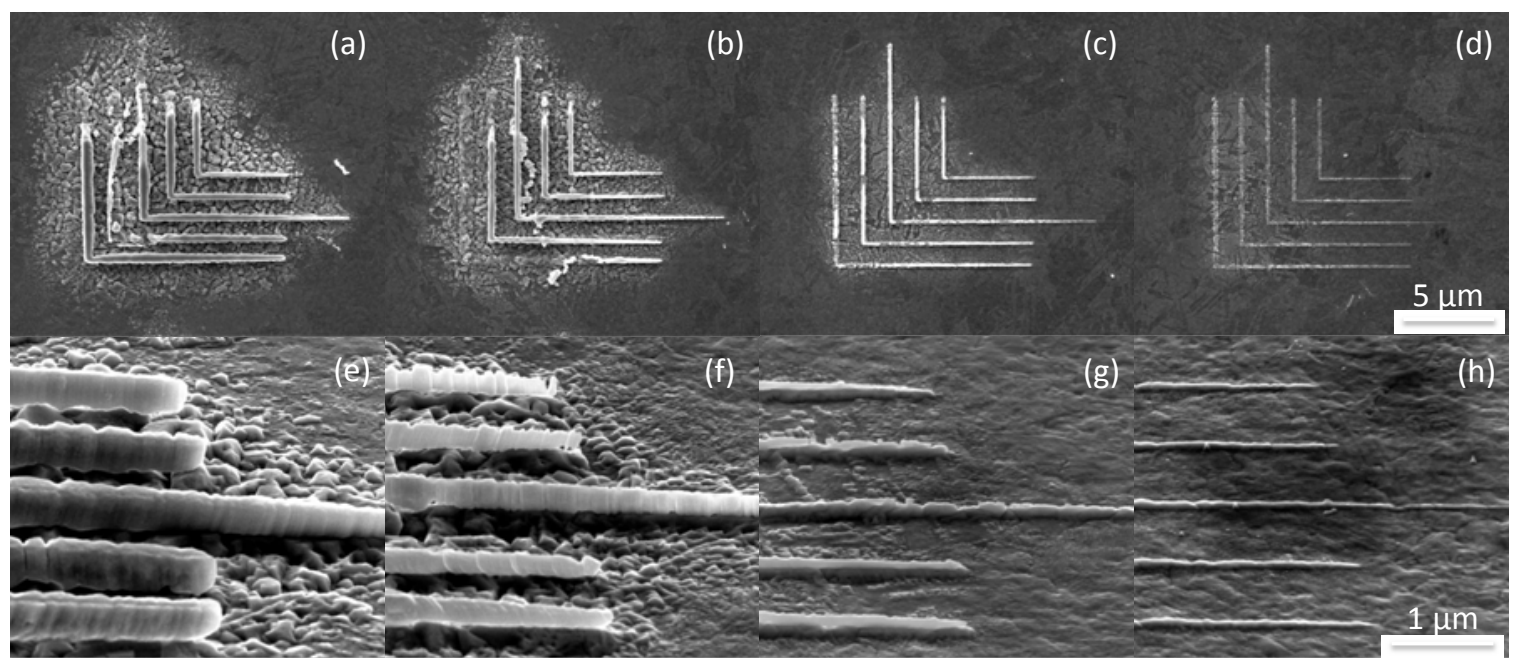

Figure 13. $1.5 \mu \mathrm{m}$ pitch nested lines deposited from an acidified copper sulfate solution with decreasing line dose: (a) $30 \mu \mathrm{C} / \mathrm{cm}$, (b) $20 \mu \mathrm{C} / \mathrm{cm}$, (c) $10 \mu \mathrm{C} / \mathrm{cm}$, and (d) $5 \mu \mathrm{C} / \mathrm{cm}$. Panels (e-h) are $60^{\circ}$ tilt micrographs of (a-d), respectively. Lines become thinner and less unintended deposition occurs as the dose decreases.

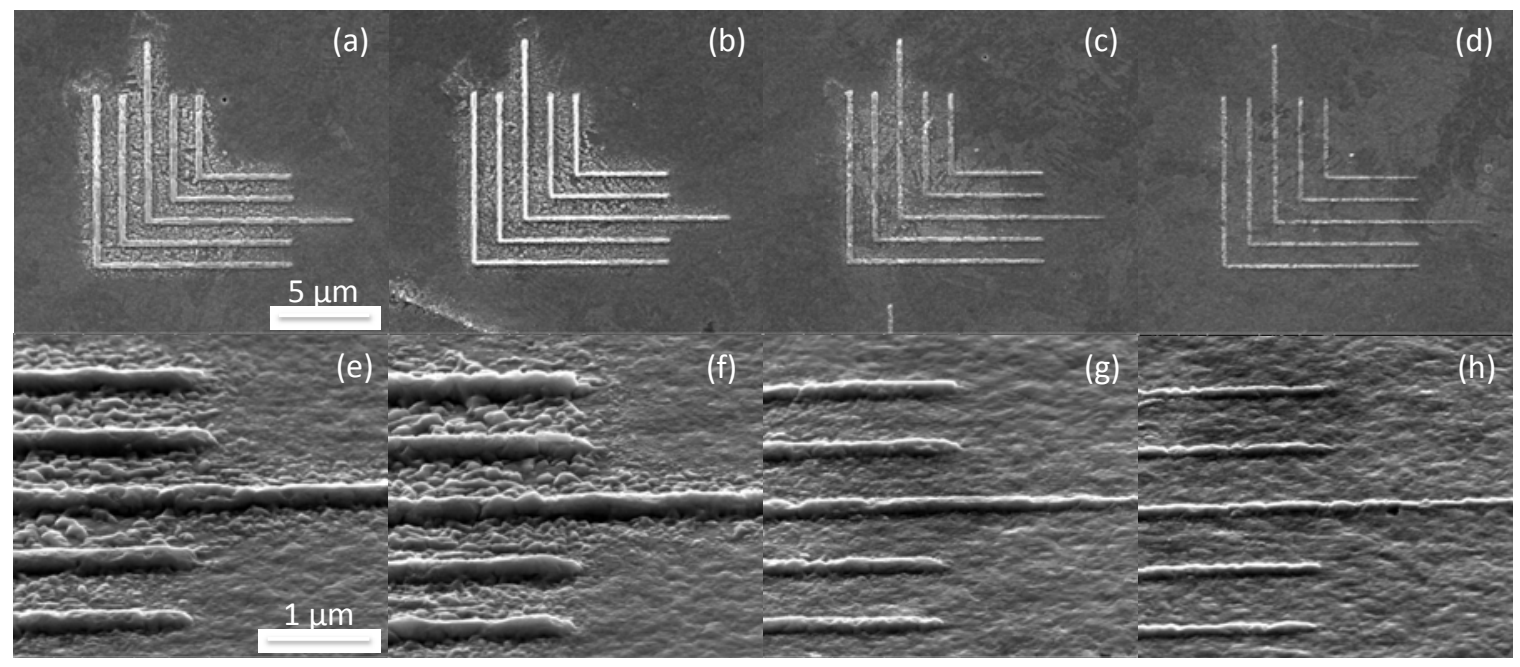

Figure 14. $1.5 \mu \mathrm{m}$ pitch nested lines deposited from an acidified copper sulfate solution with the addition of 100 ppm PEG 1000 with decreasing line dose: (a) $30 \mu \mathrm{C} / \mathrm{cm}$, (b) $20 \mu \mathrm{C} / \mathrm{cm}$, (c) $10 \mu \mathrm{C} / \mathrm{cm}$, and (d) $5 \mu \mathrm{C} / \mathrm{cm}$. Panels (e-h) are $60^{\circ}$ tilt micrographs of (a-d), respectively. Lines become thinner and less unintended deposition occurs as the dose decreases. 


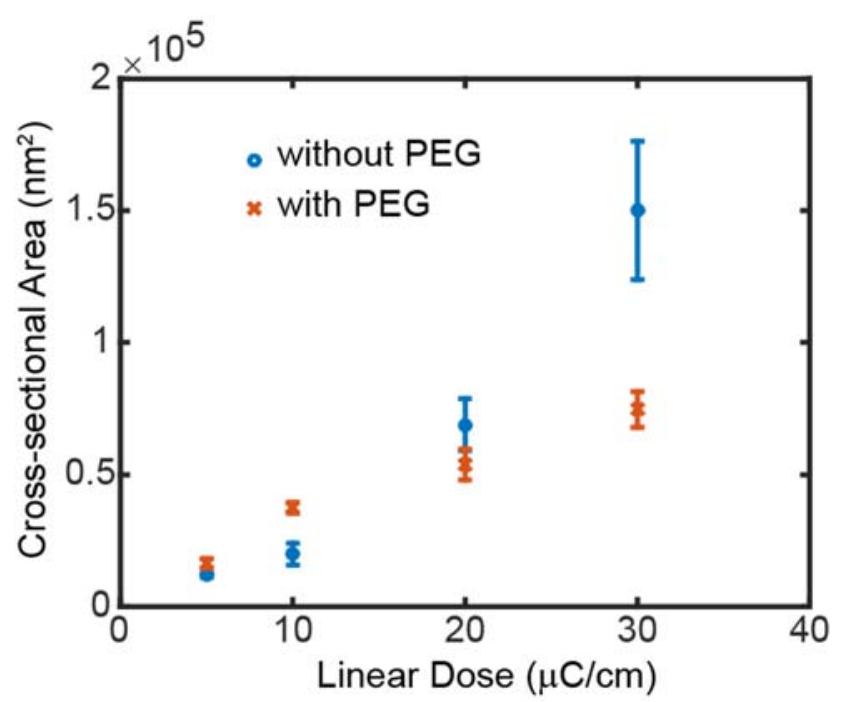

Figure 15. Cross-sectional area of deposited lines versus linear dose for the $\mathrm{CuSO}_{4}-\mathrm{H}_{2} \mathrm{SO}_{4}-$ $\mathrm{H}_{2} \mathrm{O}$ system with and without 100 ppm PEG. The suppressive effect of PEG becomes clearly evident at higher doses, as does the reduction in the variation of linewidth.

(a)

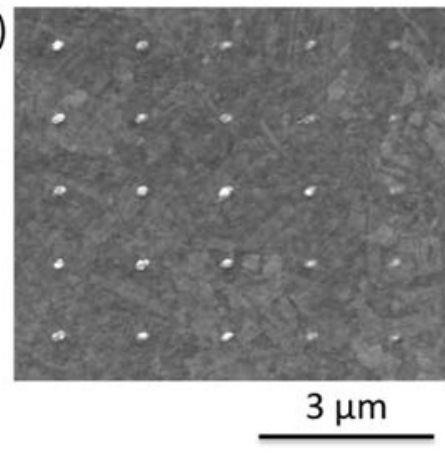

(b)

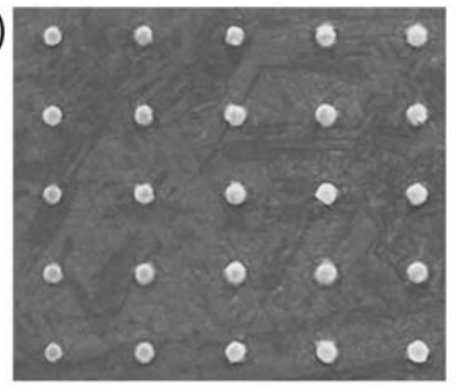

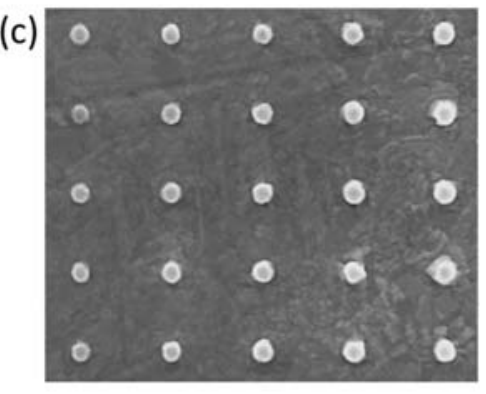

Figure 16. Dot arrays of $5 \times 5$ elements and $1.5 \mu \mathrm{m}$ spacing deposited from an acidified copper sulfate solution with the addition of 100 ppm PEG 1000 at a dose of (a) 100 pC, (b) 1000 $\mathrm{pC}$, and (c) $100 \mathrm{pC}$ x 10 pulses with a refresh time of $100 \mathrm{~ms}$, per dot. Deposition increases with dose and there is no observable effect when a refresh time is added.

Denser features were deposited to determine the highest resolution achievable. Deposition of 200 and $100 \mathrm{~nm}$ pitch nested lines from acidified copper sulfate with PEG 1000 are shown in Figure 17. The large spot at the center of the pattern in panel (a) was unintentional. The beam parked on 
this nested line pattern during deposition at another location nearby. Regardless of the extra deposit, it is evident that the $200 \mathrm{~nm}$ pitch nested lines are well resolved. Pushing the resolution further to $100 \mathrm{~nm}$ pitch nested lines proves challenging (Figure 17 (b) and (c)). As the line width and spacing between each line approach one another, the deposited lines become nearly indistinguishable.

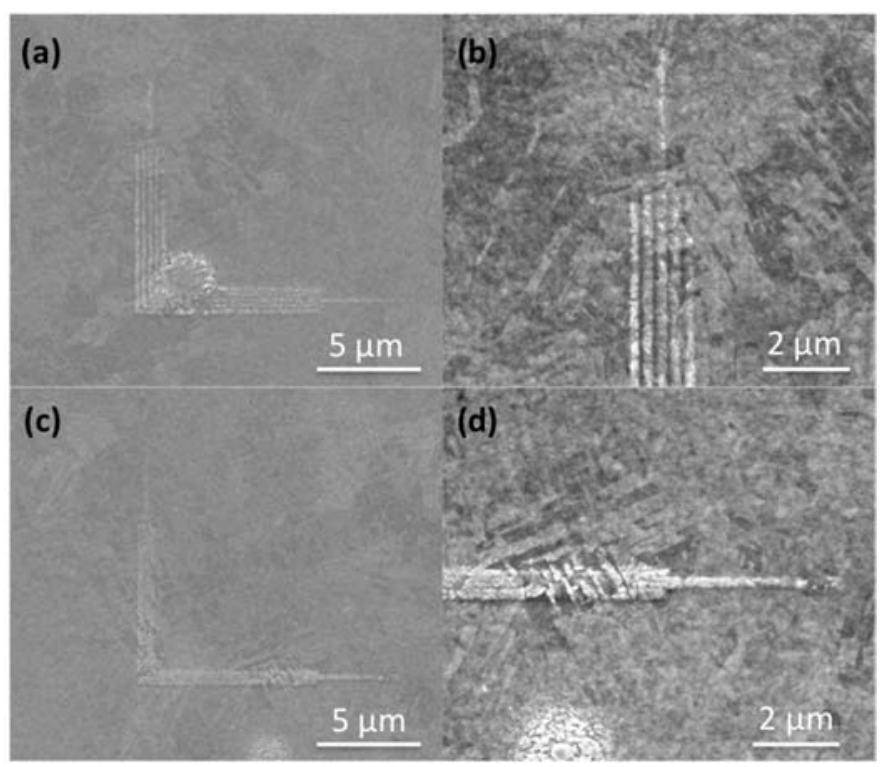

Figure 17. Nested lines deposited from an acidified copper sulfate solution at a line dose of 5 $\mu \mathrm{C} / \mathrm{cm}$ with the addition of $100 \mathrm{ppm}$ PEG 1000: (a) and (b) $200 \mathrm{~nm}$ pitch nested lines; (c) and (d) $100 \mathrm{~nm}$ pitch nested lines.

\section{Composition and Purity of Copper Deposits}

Liquid phase FEBID promises improved purity in comparison with the gas phase process. To quantify the purity of the deposits, energy dispersive x-ray spectroscopy (EDX) was performed on a large copper feature deposited from an acidified copper sulfate solution. This feature was deposited on a silicon substrate that had been sputter coated with $20 \mathrm{~nm}$ of chromium to improve adhesion, but the thickness of the feature eliminates almost any contribution from the substrate. 
The EDX spectrum and a micrograph of the deposited material are shown in Figure 18, and a comparison of EDX elemental quantification is shown in Table 1. There is only a slight increase in the carbon content of the copper deposit, about 5 at. \%, compared to the silicon reference. Moreover, no oxygen was detected in the deposit, which indicates significantly higher purity copper has been deposited in this process than from the $\mathrm{CuSO}_{4}-\mathrm{SDS}$ solution. After correcting for the background carbon signal, the actual metal content is approximately 95 at. $\%$, which is dramatically higher than reported values for $\mathrm{Cu}$ from gas FEBID deposited from hexafluoroacetyl-acetonate copper vinyl-trimethyl-silane ${ }^{41}$, copper(II) hexafluoroacetylacetonate ${ }^{42}$ which was at most 11 at. $\% \mathrm{Cu}$, and recently copper deposited with FEBID from $\mathrm{Cu}(\mathrm{I})$ and $\mathrm{Cu}(\mathrm{II})$ precursors upon post-growth annealing ${ }^{21}$ which was at most $12 \pm 2$ at. \%. Deposits formed by irradiating cooled, condensed layers of copper(II) hexafluoroacetylacetonate in UHV showed similar low copper content as deposited, but could be significantly purified by subsequent exposure to atomic oxygen and atomic hydrogen. ${ }^{35}$

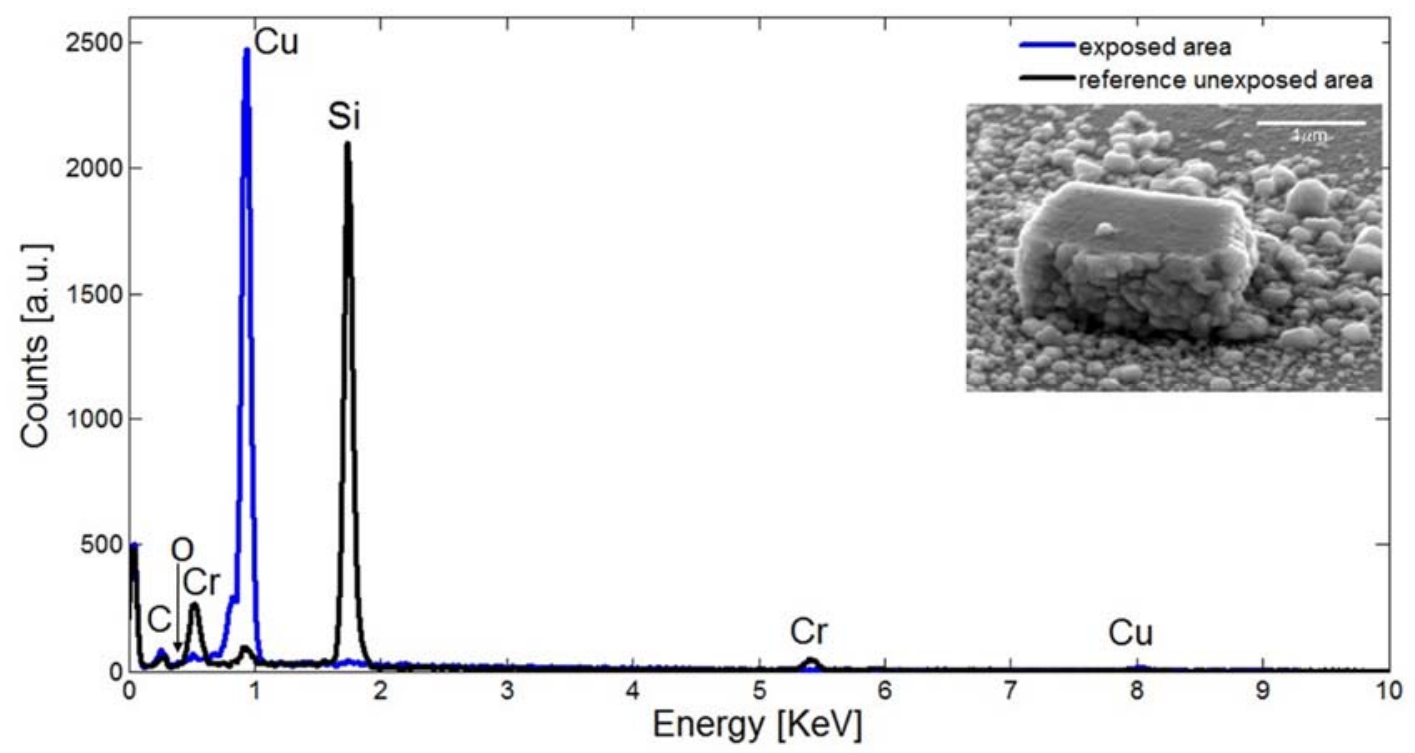

Figure 18. EDX spectra of copper deposits produced by LP-FEBID from acidified copper sulfate solution. 
Table 1. EDX quantification of $\mathrm{Cu}$ deposits from acidified copper sulfate along with Si substrate references (atomic \%).

\begin{tabular}{ccccc}
\hline & $\mathrm{C}$ & $\mathrm{O}$ & $\mathrm{Si}$ & $\mathrm{Cu}$ \\
Si ref & 8.1 & 0.49 & 91 & - \\
$\mathrm{Cu}$ Deposits & 12 & - & 0.60 & 88
\end{tabular}

EDX also reveals the copper deposits from the acidified copper sulfate solution with addition of PEG have more contamination than deposits with no additive in the mixture. An upper bound of 12 at. $\%$ carbon and 3 at.\% oxygen was seen in the spectrum of the copper feature in comparison with the silicon reference. Copper purity of this deposit was measured to be approximately 85 at.\%. Quantified elemental EDX data is presented in Table 2 and Figure 19 shows the spectrum data of the deposit compared with the bare substrate. The deposited copper features are also shown.

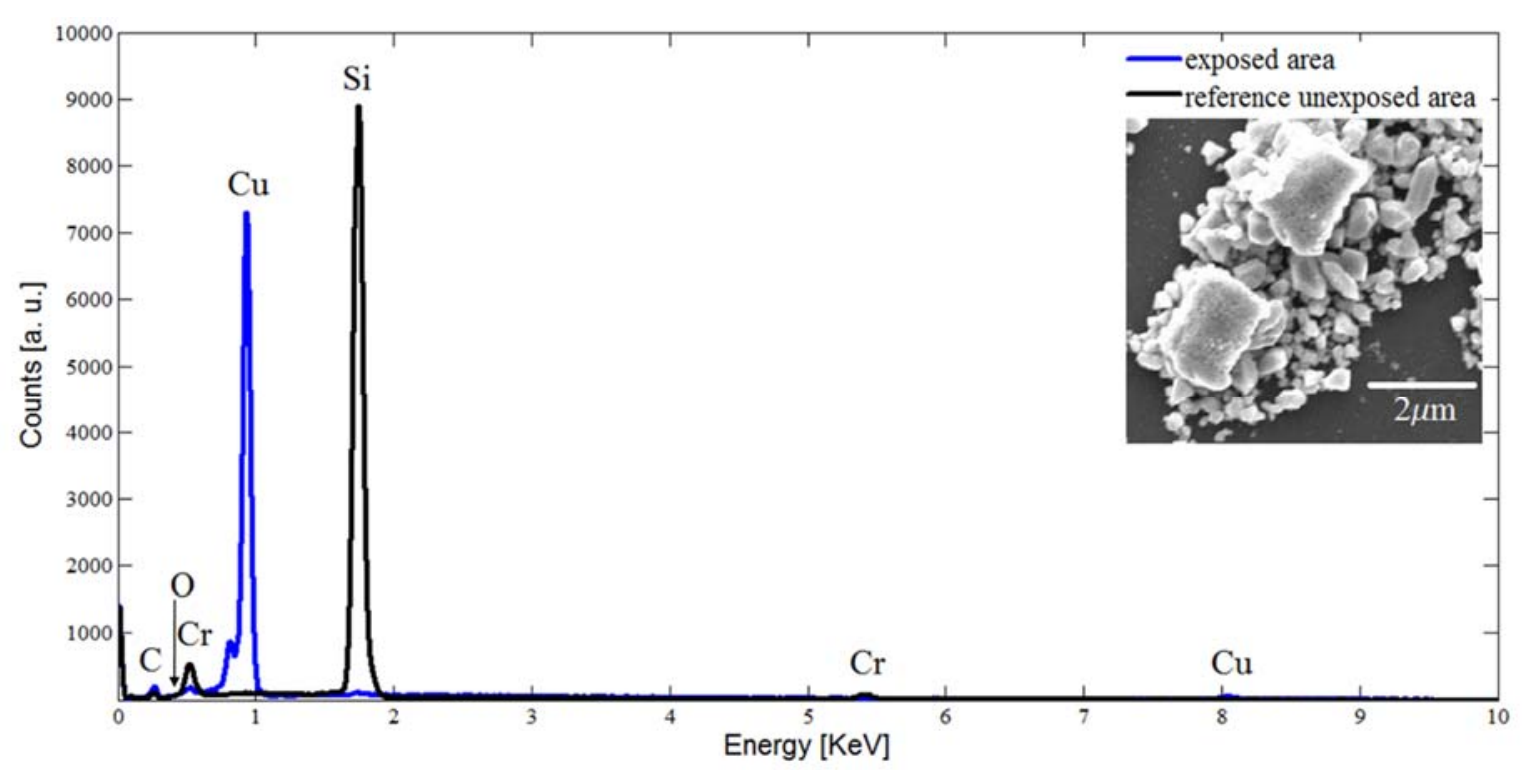

Figure 19. Energy dispersive x-ray spectra of deposits produced by LP-FEBID from $\mathrm{CuSO}_{4}$, $\mathrm{H}_{2} \mathrm{SO}_{4}$, and $\mathrm{PEG}$. 
Table 2. EDX quantification of $\mathrm{Cu}$ deposits from acidified copper sulfate with the addition of PEG, along with Si substrate references (atomic \%).

\begin{tabular}{rcccc}
\hline & $\mathrm{C}$ & $\mathrm{O}$ & $\mathrm{Si}$ & $\mathrm{Cu}$ \\
Si reference & 8.2 & 0.49 & 91 & - \\
$\mathrm{Cu}$ Deposits & 20 & 2.4 & - & 78 \\
\hline
\end{tabular}

\section{Deposition Mechanisms}

There is discussion in the literature as to the relative contributions of electrochemical and radiation chemical processes in LP-FEBID., $93,14,36,45$ The reaction may be surface mediated, occurring in solution, or a combination of the two. In the first case, the e-beam is thought to create a localized virtual cathode on the substrate, thus enabling the electrodeposition of copper. ${ }^{13}$ In this scenario, copper ions are reduced to copper metal at the interface by direct transfer of electrons. This deposition process proceeds according to the following half reaction. ${ }^{43}$

$$
\mathrm{Cu}_{(\mathrm{aq})}^{2+}+2 e^{-} \leftrightarrow \mathrm{Cu}_{(\mathrm{s})}(E=0.340 \mathrm{~V})
$$

Alternatively, the reaction may be driven by radiation chemistry. In this case, a primary electron $\left(e_{p r}^{-}\right)$ionizes water and produces a secondary electron. This electron may ionize additional water molecules, or lose energy by other pathways until it becomes a solvated electron, $e^{-}(a q)$. The ionized water molecule subsequently produces a hydronium ion and a hydroxyl radical. The net reaction is

$$
2 \mathrm{H}_{2} \mathrm{O} \stackrel{e_{p r}^{-}}{\rightarrow} e^{-}(a q)+\mathrm{H}_{3} \mathrm{O}^{+}+\mathrm{OH}
$$

The solvated electron can directly reduce $\mathrm{Cu}^{2+}$ to $\mathrm{Cu}^{1+}\left(k=3 \times 10^{10} M^{-1} S^{-1}\right)^{44}$ and then $\mathrm{Cu}^{1+}$ to $\mathrm{Cu}(\mathrm{s})$. There is also an alternative pathway that may be important for acidic solutions. Specifically, the solvated electron can react with hydronium to form atomic hydrogen ${ }^{4}$

$$
e^{-}(a q)+H_{3} O^{+} \rightarrow H+H_{2} O\left(k=2 \times 10^{10} M^{-1} S^{-1}\right)
$$


Atomic hydrogen can then serve as the reducing agent, though with a significantly slower reaction rate. $^{36}$

$$
C u^{2+}+H \rightarrow C u^{1+}+H^{+}\left(k=9 \times 10^{7} M^{-1} S^{-1}\right)
$$

Of course, $\mathrm{Cu}^{1+}$ can also be reduced to metallic copper through the disproportionation reaction

$$
C u^{1+}+C u^{1+} \rightarrow C u(s)+C u^{2+}
$$

The deposit itself is built up by subsequent nucleation and growth from copper atoms or clusters.

The efficiency of copper deposition under some conditions $(<1.4$ primary electrons/Cu atom) suggests that a radiation-chemical mechanism likely contributes as a purely electrochemical mechanism would be limited to 2 primary electrons/Cu atom. In addition, Figure 20 shows $1 \mu \mathrm{m}$ pitch nested copper lines on the electrodeposited copper film with additional evidence of copper reduction in solution. The first pattern (a) is deposited from acidified copper sulfate solution and the second pattern (b) is deposited from the same solution with the addition of Triton X-100. Although there are clean patterns with sharp corners for the nested lines in both, there are two groups of patterns that have been deposited during the FEBID process at the same time; one on the substrate and the other in the solution. During the dehydration step, the pattern in the liquid floated away and re-deposited at a new location on the substrate. It should be noted that this double patterning was rarely observed, presumably because copper particles formed in solution did not create well-connected structures or because the secondary structure did not adhere to the substrate.

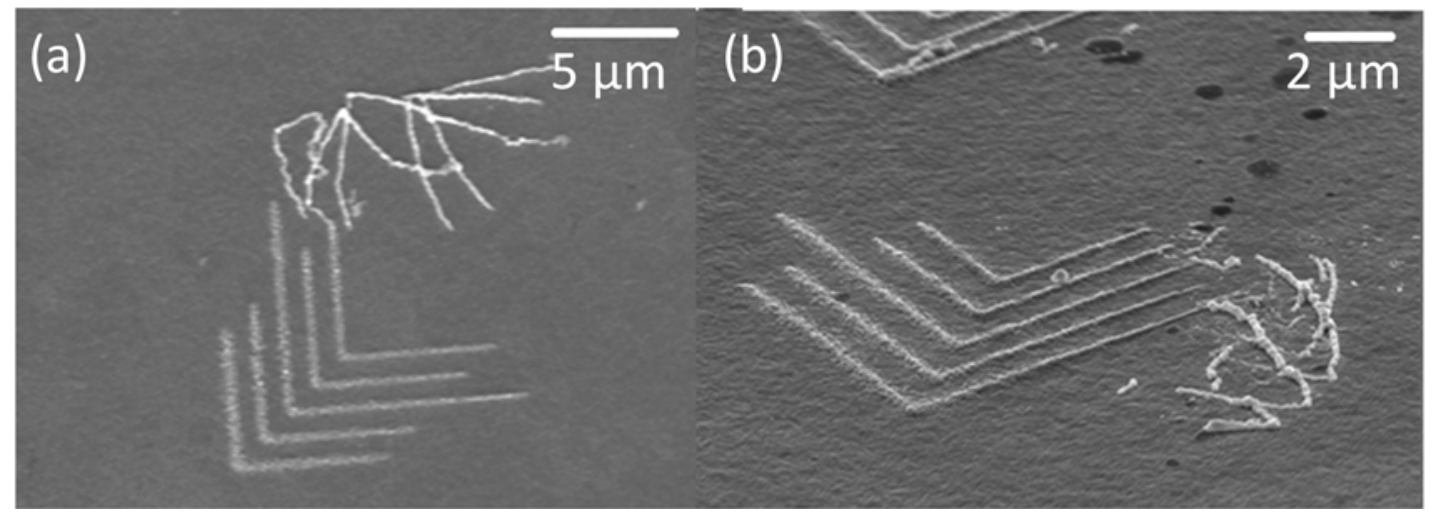


Figure 20. $1 \mu \mathrm{m}$ nested lines on an electrodeposited copper film deposited from (a) acidified copper sulfate solution and (b) acidified copper sulfate solution with Triton X-100 additive. A second, distorted, copy of the pattern was observed nearby.

\section{CONCLUSION}

High purity copper can be deposited from aqueous solutions of copper sulfate, and deposition efficiencies greatly exceed those observed for metalorganic, gas-phase copper precursors. Addition of surfactants to these solutions enables dense, high resolution patterning (100 nm pitch nested-Ls) and increases the area available for deposition. This represents a significant improvement in the resolution of liquid-phase FEBID on bulk substrates. Previous efforts have only yielded $<100 \mathrm{~nm}$ features for isolated lines, ${ }^{14}$ never for dense lines and spaces that truly reveal resolution. We found Triton X-100 is appropriate for the cooled experimental conditions in an ESEM, and it reduces precipitates and sulfur contamination compared to SDS. Sulfuric acid stabilizes the liquid films by decreasing the vapor pressure of the solutions; however, without surfactants, the substrate area available for direct writing only extends over a few microns.

Addition of Triton X-100 or PEG to the acidified copper sulfate solution thins the liquid film and produces finer grained structures. The highest resolution was obtained with Triton X-100 in acidified $\mathrm{CuSO}_{4}$ while the highest aspect ratio structures were obtained with PEG in acidified $\mathrm{CuSO}_{4}$. For the precursor solution studied here, thick, dense lines cannot be patterned without significant unintended deposition. Thus, until a means to mitigate this extra deposition is found, practical application of the technique will be limited to thin lines and/or low density patterns. EDX studies revealed that the purity of copper deposits from LP-FEBID is dramatically improved compared to the standard gas phase FEBID processes. Specifically, approximately 95 at. $\%$ copper 
was deposited from acidic copper sulfate solution. Addition of PEG improved pattern fidelity, while only reducing the purity of the deposit to $\sim 85$ at.\% which is still remarkably high for FEBID. The effects of additives were similar to those observed for electrodeposition of copper. However, significant evidence of radiation-chemical processes was also observed highlighting the complexity of the LP-FEBID process.

\section{ACKNOWLEDGEMENTS}

This material is based upon work supported by the National Science Foundation under Grant Numbers CMMI-1125998, CMMI-1538650, and ECCS-1542164. The authors thank Professor Kathleen Dunn, SUNY Polytechnic Institute, for providing the electrodeposited copper samples. This study used facilities provided by the University of Kentucky Center for Nanoscale Science and Engineering (CeNSE) and the University of Kentucky Electron Microscopy Center (EMC). 


\section{REFERENCES}

1. Donev, E. U.; Schardein, G.; Wright, J. C.; Hastings, J. T., Substrate effects on the electronbeam-induced deposition of platinum from a liquid precursor. Nanoscale 2011, 3 (7), 2709-17.

2. Donev, E. U.; Hastings, J. T., Electron-Beam-Induced Deposition of Platinum from a Liquid Precursor. Nano Letters 2009, 9 (7), 2715-2718.

3. Donev, E. U.; Hastings, J. T., Liquid-precursor electron-beam-induced deposition of Pt nanostructures: dose, proximity, resolution. Nanotechnology 2009, 20 (50), 505302.

4. Schardein, G.; Donev, E. U.; Hastings, J. T., Electron-beam-induced deposition of gold from aqueous solutions. Nanotechnology 2011, 22 (1), 015301.

5. Ocola, L. E.; Joshi-Imre, A.; Kessel, C.; Chen, B.; Park, J.; Gosztola, D.; Divan, R., Growth characterization of electron-beam-induced silver deposition from liquid precursor. Journal of Vacuum Science \& Technology B 2012, 30 (6).

6. Bresin, M.; Nehru, N.; Hastings, J. T. In Focused electron-beam induced deposition of plasmonic nanostructures from aqueous solutions, Proc. SPIE 8613, Advanced Fabrication Technologies for Micro/Nano Optics and Photonics, 2013; pp 861306-861306-6.

7. Fisher, J. S.; Kottke, P. A.; Kim, S.; Fedorov, A. G., Rapid Electron Beam Writing of Topologically Complex 3D Nanostructures Using Liquid Phase Precursor. Nano Letters 2015, 15 (12), 8385-8391.

8. Jesse, S.; Borisevich, A. Y.; Fowlkes, J. D.; Lupini, A. R.; Rack, P. D.; Unocic, R. R.; Sumpter, B. G.; Kalinin, S. V.; Belianinov, A.; Ovchinnikova, O. S., Directing Matter: Towards Atomic Scale 3D Nanofabrication. ACS Nano 2016. 
9. Bresin, M.; Chamberlain, A.; Donev, E. U.; Samantaray, C. B.; Schardien, G. S.; Hastings, J. T., Electron-Beam-Induced Deposition of Bimetallic Nanostructures from Bulk Liquids. Angew. Chem.-Int. Edit. 2013, 52 (31), 8004-8007.

10. Bresin, M.; Nadimpally, B. R.; Nehru, N.; Singh, V. P.; Hastings, J. T., Site-specific growth of CdS nanostructures. Nanotechnology 2013, 24 (50).

11. Lai, S.-E.; Hong, Y.-J.; Chen, Y.-T.; Kang, Y.-T.; Chang, P.; Yew, T.-R., Direct-Writing of $\mathrm{Cu}$ Nano-Patterns with an Electron Beam. Microsc. microanal. 2015, FirstView, 1-5.

12. den Heijer, M.; Shao, I.; Radisic, A.; Reuter, M. C.; Ross, F. M., Patterned electrochemical deposition of copper using an electron beam. Apl Materials 2014, 2 (2).

13. Randolph, S. J.; Botman, A.; Toth, M., Capsule-free fluid delivery and beam-induced electrodeposition in a scanning electron microscope. RSC Advances 2013, 3 (43), 20016-20023.

14. Bresin, M.; Botman, A.; Randolph, S. J.; Straw, M.; Hastings, J. T., Liquid Phase ElectronBeam-Induced Deposition on Bulk Substrates Using Environmental Scanning Electron Microscopy. Microsc. microanal. 2014, 20 (02), 376-384.

15. Utke, I.; Luisier, A.; Hoffmann, P.; Laub, D.; Buffat, P. A., Focused-electron-beam-induced deposition of freestanding three-dimensional nanostructures of pure coalesced copper crystals. Applied Physics Letters 2002, 81 (17), 3245-3247.

16. Luisier, A.; Utke, I.; Bret, T.; Cicoira, F.; Hauert, R.; Rhee, S. W.; Doppelt, P.; Hoffmann, P., Comparative study of $\mathrm{Cu}$ precursors for 3D focused electron beam induced deposition. Journal of the Electrochemical Society 2004, 151 (8), C535-C537.

17. Bret, T.; Utke, I.; Gaillard, C.; Hoffmann, P., Periodic structure formation by focused electron-beam-induced deposition. Journal of Vacuum Science \& Technology B 2004, 22 (5), 2504-2510. 
18. Hau-Riege, S. P.; Thompson, C. V., In situ transmission electron microscope studies of the kinetics of abnormal grain growth in electroplated copper films. Applied Physics Letters 2000, 76 (3), 309-311.

19. Brongersma, S.; Vanstreels, K.; Wu, W.; Zhang, W.; Ernur, D.; D'Haen, J.; Terzieva, V.; Van Hove, M.; Clarysse, T.; Carbonell, L. In Influence of copper purity on microstructure and electromigration, Interconnect Technology Conference, 2004. Proceedings of the IEEE 2004 International, IEEE: 2004; pp 45-47.

20. Szkudlarek, A.; Vaz, A. R.; Zhang, Y. C.; Rudkowski, A.; Kapusta, C.; Erni, R.; Moshkalev, S.; Utke, I., Formation of pure $\mathrm{Cu}$ nanocrystals upon post-growth annealing of $\mathrm{Cu}-\mathrm{C}$ material obtained from focused electron beam induced deposition: comparison of different methods (vol 6, pg 1508, 2015). Beilstein Journal of Nanotechnology 2015, 6, 1935-1936.

21. Szkudlarek, A.; Vaz, A. R.; Zhang, Y. C.; Rudkowski, A.; Kapusta, C.; Erni, R.; Moshkalev, S.; Utke, I., Formation of pure $\mathrm{Cu}$ nanocrystals upon post-growth annealing of $\mathrm{Cu}-\mathrm{C}$ material obtained from focused electron beam induced deposition: comparison of different methods. Beilstein Journal of Nanotechnology 2015, 6, 1508-1517.

22. A. Syam, Amjda; Hastings, J. Todd. "Electron-Beam Induced Deposition of Highly Conductive Copper Nanowires from Bulk Liquids," 60th International Conference on Electron, Ion, and Photon Beam Technology and Nanofabrication (EIPBN), 2016.

23. Weast, Robert C., Melvin J. Astle, and William H. Beyer. CRC handbook of chemistry and physics. Vol. 69. Boca Raton, FL: CRC press, 1988.

24. Holler, Homer Denison, and Elmer Line Peffer. "The relation between composition and density of aqueous solutions of copper sulphate and sulphuric acid." Journal of the Franklin Institute 181.4 (1916): 568. 
25. Fontell, K., Liquid crystallinity in lipid-water systems. Molecular Crystals and Liquid Crystals 1981, 63 (1), 59-82.

26. Nakayama, H.; Shinoda, K.; Hutchinson, E., The Effect of Added Alcohols on the Solubility and the Krafft Point of Sodium Dodecyl Sulfate. The Journal of Physical Chemistry 1966, 70 (11), $3502-3504$.

27. Kekicheff, P.; Grabielle-Madelmont, C.; Ollivon, M., Phase diagram of sodium dodecyl sulfate-water system: 1. A calorimetric study. Journal of colloid and interface science 1989, 131 (1), 112-132.

28. Mukerjee, P.; Mysels, K. J. Critical micelle concentrations of aqueous surfactant systems; DTIC Document: 1971.

29. Orphanou, M.; Leontidis, E.; Kyprianidou-Leodidou, T.; Koutsoukos, P.; Kyriacou, K. C., Study of copper sulfide crystallization in PEO-SDS solutions. Langmuir 2004, 20 (13), 5605-12.

30. Ahir , S. V., P. G. Petrov, and E. M. Terentjev. "Rheology at the phase transition boundary: 2. Hexagonal phase of Triton X100 surfactant solution. Langmuir 2002, 18 (24), 9140-9148.

31. Ng, S. C.; Teh, H. C.; Hosea, T. J. C.; Gan, L. M., A Brillouin scattering study if the sol-gel transition in triton X-100-water systems. Physics Letters A 1984, 105 (3), 153-156.

32. Jaeckervoirol, A.; Ponche, J. L.; Mirabel, P., Vapor-Pressures in the Ternary-System Water Nitric-Acid Sulfuric-Acid at Low-Temperatures. J Geophys Res-Atmos 1990, 95 (D8), 1185711863.

33. Fairbrother, D. H.; Johnston, H.; Somorjai, G., Electron Spectroscopy Studies of the Surface Composition in the $\mathrm{H}_{2} \mathrm{SO}_{4} / \mathrm{H}_{2} \mathrm{O}$ Binary System. The Journal of Physical Chemistry 1996, 100 (32), 13696-13700. 
34. Zeleznik, F. J., Thermodynamic properties of the aqueous sulfuric acid system to $350 \mathrm{~K}$. Journal of physical and chemical reference data 1991, 20 (6), 1157-1200.

35. Massucci, M.; Clegg, S. L.; Brimblecombe, P., Equilibrium vapor pressure of $\mathrm{H}_{2} \mathrm{O}$ above aqueous $\mathrm{H}_{2} \mathrm{SO}_{4}$ at low temperature. J Chem Eng Data 1996, 41 (4), 765-778.

36. Boehme, L.; Bresin, M.; Aurélien, B.; James, R.; Hastings, J. T., Focused electron beam induced etching of copper in sulfuric acid solutions. Nanotechnology 2015, 26 (49), 495301.

37. Andricacos, P. C.; Uzoh, C.; Dukovic, J. O.; Horkans, J.; Deligianni, H., Damascene copper electroplating for chip interconnections. IBM Journal of Research and Development 1998, 42 (5), 567-574.

38. Boehme, L.; Landau, U., Rapid screening of plating additives for bottom-up metallization of nano-scale features. Journal of Applied Electrochemistry 2016, 46 (1), 39-46.

39. Kondo, K.; Matsumoto, T.; Watanabe, K., Role of additives for copper damascene electrodeposition experimental study on inhibition and acceleration effects. Journal of The Electrochemical Society 2004, 151 (4), C250-C255.

40. Hebert, K. R., Role of chloride ions in suppression of copper electrodeposition by polyethylene glycol. Journal of The Electrochemical Society 2005, 152 (5), C283-C287.

41. Ochiai, Y.; Fujita, J. i.; Matsui, S., Electron-beam-induced deposition of copper compound with low resistivity. Journal of Vacuum Science \&amp; Technology B 1996, 14 (6), 3887-3891.

42. Friedli, V.; Utke, I.; Mølhave, K.; Michler, J., Dose and energy dependence of mechanical properties of focused electron-beam-induced pillar deposits from $\mathrm{Cu}(\mathrm{C} 5 \mathrm{HF} 6 \mathrm{O} 2) 2$. Nanotechnology 2009, 20 (38), 385304.

43. Bard, A. J.; Faulkner, L. R., Electrochemical Methods: Fundamentals and Applications. Wiley: 2000. 
44. Buxton, G. V.; Greenstock, C. L.; Helman, W. P.; Ross, A. B., Critical Review of rate constants for reactions of hydrated electrons, hydrogen atoms and hydroxyl radicals $(\cdot \mathrm{OH} / \cdot \mathrm{O}-$ in Aqueous Solution. Journal of Physical and Chemical Reference Data 1988, 17 (2), 513-886.

45. Unocic, R. R; Lupini, A. R.; Borisevich, A. Y.; Cullen, D. A.; Kalinina, S. V.; Jesse, S., Direct-write liquid phase transformations with a scanning transmission electron microscope. Nanoscale 2016, 8, 15581-15588. 